Final report for project:

Next generation aerosol-cloud microphysics for advanced high-resolution climate predictions

DOE Regional and Global Climate Modeling (RCGM) Program

Award\# : DE-SC0001236

Grant ER64840

The Board of Regents of the University of Wisconsin System

May 2012

August 15, 2011 - August 14, 2012

Ralf Bennartz (Principal Investigator)

Department of Atmospheric and Oceanic Sciences

University of Wisconsin - Madison, Wisconsin

Kevin P. Hamilton (Co-Principal Investigator)

International Pacific Research Center (IPRC)

University of Hawaii

Vaughan T. J. Phillips, Yuqing Wang (Co-Investigators)

Department of Meteorology

University of Hawaii

Jean-Louis Brenguier (Co-Investigator)

Centre Nationale de la Recherche Meteorologique (CNRM)

Meteo-France, Toulouse, France 


\section{1) Project objective}

The three top-level project goals are:

- We proposed to develop, test, and run a new, physically based, scaleindependent microphysical scheme for those cloud processes that most strongly affect greenhouse gas scenarios, i.e. warm cloud microphysics. In particular, we proposed to address cloud droplet activation, autoconversion, and accretion.

- The new, unified scheme was proposed to be derived and tested using the University of Hawaii's IPRC Regional Atmospheric Model (iRAM).

- The impact of the new parameterizations on climate change scenarios will be studied. In particular, the sensitivity of cloud response to climate forcing from increased greenhouse gas concentrations will be assessed.

\section{2) Current status}

Here, we briefly address the current project status with respect to the three major goals formulated above:

\begin{tabular}{|c|c|c|}
\hline Goal & Description & Status \\
\hline 1 & $\begin{array}{l}\text { Develop, test, and run a new, } \\
\text { physically based, scale-independent } \\
\text { microphysical scheme for those cloud } \\
\text { processes that most strongly affect } \\
\text { greenhouse gas scenarios, i.e. warm } \\
\text { cloud microphysics. }\end{array}$ & $\begin{array}{l}\text { This method has been } \\
\text { developed, see } \\
\text { Bennartz et al., } \\
\text { (2011a) }\end{array}$ \\
\hline 2 & $\begin{array}{l}\text { Scheme tested using the University of } \\
\text { Hawaii's IPRC Regional Atmospheric } \\
\text { Model }\end{array}$ & $\begin{array}{l}\text { Initially tests within } \\
\text { iRam were performed } \\
\text { in Bennartz et al., } \\
\text { (2011a). Further } \\
\text { testing and refinement } \\
\text { of the method is } \\
\text { underway and will } \\
\text { lead to a detailed } \\
\text { follow-up publication }\end{array}$ \\
\hline 3 & $\begin{array}{l}\text { The impact of the new } \\
\text { parameterizations on climate change } \\
\text { scenarios will be studied. In } \\
\text { particular, the sensitivity of cloud } \\
\text { response to climate forcing from } \\
\text { increased greenhouse gas } \\
\text { concentrations will be assessed. }\end{array}$ & $\begin{array}{l}\text { This part of the project } \\
\text { has been finished as } \\
\text { well. Results are } \\
\text { summarized in Lauer } \\
\text { et al. (2012). }\end{array}$ \\
\hline
\end{tabular}




\section{3) Peer-reviewed published papers from this project:}

Four peer-reviewed papers have come out of this project. We list these publications here together with highlighted results. The full PDFs are attached to this report.

a) Bennartz, R., A. Lauer, and J. L. Brenguier, 2011a: Scale-aware integral constraints on autoconversion and accretion in regional and global climate models. Geophys. Res. Lett., doi:10.1029/2011GL047618,accepted 25 April 2011.

- We describe a novel method to constrain autoconversion and accretion rates in climate models.

- The method offers two desirable features that might ultimately help to effectively eliminate autoconversion efficiency as a free tuning parameter in climate models.

- The new method was implemented into the University of Hawaii's regional climate model iRAM.

- A series of test integrations were performed at horizontal resolutions ranging from $0.25^{\circ} \times 0.25^{\circ}$ to $2^{\circ} \times 2^{\circ}$.

- The constrained approach was compared with a conventional approach commonly found in current climate models. Comparisons with an observational climatology of cloud liquid water path reveal significant improvements, in particular a better consistency between different model resolutions.

b) Lauer, A., K. Hamilton, Y. Wang, V. Phillips, R. Bennartz, 2010: The impact of global warming on marine boundary layer clouds over the eastern Pacific - A regional model study, Journal of Climate, 23, 5844-5863

- Cloud simulations and cloud-climate feedbacks in the tropical and subtropical eastern Pacific region in 16 state-of-the-art coupled global climate models and in the International Pacific Research Center Regional Atmospheric Model (iRAM) are examined.

- In contrast to the coupled global models, iRAM simulates mean clouds and interannual cloud variations that are quite similar to those observed in this region.

- Cloud-climate feedbacks in iRAM are investigated running several global warming scenarios. All of these simulations show a distinct reduction in lowlevel cloud amount, particularly in the stratocumulus regime, resulting in positive local feedback parameters in these regions.

- The cloud-climate feedback averaged over the same east Pacific region was also calculated from the simulations for each of the 16 global models with all results less than the values obtained in the comparable iRAM simulations.

- In the global models, the cloud feedback in the full tropical-subtropical zone, 
which largely determines the global climate sensitivity, is strongly correlated with the east Pacific cloud feedback. This suggests that the iRAM results provide some support for the high end of current estimates of global climate sensitivity.

\section{c) Bennartz, R., J. Fan, J. Rausch, L. R. Leung, and A. K. Heidinger, 2011b:}

Pollution from China increases cloud droplet number, suppresses rain over the East China Sea, Geophys. Res. Lett., doi:10.1029/2011GL047235, accepted 3 April 2011.

- We show that $\mathrm{SO}_{2}$ and $\mathrm{NO}_{\mathrm{x}}$ from China significantly affect wintertime clouds and precipitation over the East China Sea downwind of major emission sources.

- Satellite observations show an increase of cloud droplet number concentration from less than $200 \mathrm{~cm}^{-3}$ in the 1980s to more than $300 \mathrm{~cm}^{-3}$ in 2005.

- In the same time period, precipitation frequency reported by voluntary ship observers was reduced from more than $30 \%$ to less than $20 \%$ of the time.

- A back trajectory analysis showed the pollution in the investigation area to originate from the Shanghai-Nanjing and Jinan industrial areas.

- A mesoscale model sensitivity study was performed, isolating the effects of changes in emissions of the aerosol precursors $\mathrm{SO}_{2}$ and $\mathrm{NO}_{\mathrm{x}}$ on clouds and precipitation using a state-of-the-art mesocale model including chemistry and aerosol indirect effects.

- Similar changes in cloud droplet number concentration over the East China Sea were obtained when the current industrial emissions in China were reduced to the 1980 s levels.

\section{d) Lauer, A., R. Bennartz, K. Hamilton, and Y. Wang, 2012:}

Modeling the response of marine boundary layer clouds to global warming: The impact of subgrid scale precipitation formation, J. Climate doi:

http://dx.doi.org/10.1175/JCLI-D-11-00623.1.

- We examine the impact of model tuning on results for the modeled cloud feedback in a regional climate model by applying the scale-aware parameterization for precipitation formation developed in this project (Bennartz et al., 2011).

- Simulations with the University of Hawaii's regional climate model (iRAM) show that the scale-aware parameterization produces consistent results that are in good agreement with observations throughout the tested horizontal model resolutions $\left(0.25^{\circ} \times 0.25^{\circ}\right.$ to $\left.2^{\circ} \times 2^{\circ}\right)$ without the need for model tuning.

- We conduct a series of global warming experiments to investigate the impact of the treatment of the precipitation formation efficiency on modeled cloudclimate feedbacks.

- The cloud responses to global warming in simulations with a conventionally tuned precipitation formation scheme and with the scale-aware method 
were found to be quite consistent, although differences in individual regions of $\sim 10-30 \%$ are evident.

\section{4) Press coverage}

Our publications have received some attention in the general media.

ScienceNews (Bennartz et al., 2011b) http://www.sciencenews.org/view/generic/id/330775/title/News_in_Brief_Ear thEnvironment

New Scientist (Lauer et al., 2010) http://www.newscientist.com/article/mg20827893.400-goodbye-grey-skieshello-extra-warming.html?DCMP=0TC-rss\&nsref=environment

Discovery (Lauer et al., 2010) http://news.discovery.com/earth/clouds-may-make-warming-worse.html

\section{Report Climate Science (Lauer et al., 2010)}

http://www.reportingclimatescience.com/news-stories/article/model-showsclouds-will-amplify-climate-change.html

\section{5) Attachments}

PDF copies latest paper published. (For the earlier papers see the 2011 progress report). 


\title{
Modeling the Response of Marine Boundary Layer Clouds to Global Warming: The Impact of Subgrid-Scale Precipitation Formation
}

\author{
AXEL LAUER \\ International Pacific Research Center, University of Hawaii at Manoa, Honolulu, Hawaii \\ RALF BENNARTZ \\ Department of Atmospheric and Oceanic Sciences, University of Wisconsin-Madison, Madison, Wisconsin \\ KeVIn Hamilton AND YuQING WANG \\ International Pacific Research Center, and Department of Meteorology, University of Hawaii at Manoa, \\ Honolulu, Hawaii
}

(Manuscript received 25 October 2011, in final form 27 February 2012)

\begin{abstract}
An important parameter often adjusted to achieve agreement between simulated and observed radiative fluxes in climate models is the rain formation efficiency. This adjustment has been justified as accounting for the effects of subgrid-scale variability in cloud properties, but this tuning approach is rather arbitrary. This study examines results from a regional climate model with precipitation formation schemes that have been conventionally tuned, and it compares them with simulations employing a recently developed scheme that uses satellite observations to explicitly account for the subgrid-scale variability of clouds ("integral constraint method"). Simulations with the International Pacific Research Center's Regional Atmospheric Model (iRAM) show that the integral constraint method is capable of simulating cloud fields over the eastern Pacific that are in good agreement with observations, without requiring model tuning. A series of global warming simulations for late twenty-first-century conditions is performed to investigate the impact of the treatment of the precipitation formation efficiency on modeled cloud-climate feedbacks. The results with the integral constraint method show that the simulated cloud feedbacks have similar patterns at all the model resolutions considered (grid spacings of 50,100, and $200 \mathrm{~km}$ ), but there are some quantitative differences (with smaller feedbacks at finer resolution). The cloud responses to global warming in simulations with a conventionally tuned autoconversion scheme and with the integral constraint method were found to be quite consistent, although differences in individual regions of $\sim 10 \%-30 \%$ are evident. No conclusions can be drawn from this study on the validity of model tuning for thick clouds and mixed phase or ice clouds, however.
\end{abstract}

\section{Introduction}

Clouds are key components driving weather and climate by reflecting significant amounts of incoming solar radiation and absorbing outgoing thermal radiation, and they play a pivotal role in the hydrological cycle (e.g., Hartmann and Doelling 1991). The response of clouds to global warming, and of low-level clouds in particular, is still poorly understood and remains a major uncertainty

Corresponding author address: Axel Lauer, IPRC/SOEST, University of Hawaii at Manoa, 1680 East-West Rd., Post Bldg. 401, Honolulu, HI 96822.

E-mail: lauera@hawaii.edu in current projections of future climate (e.g., Bony and Dufresne 2005; Stowasser and Hamilton 2006; Solomon et al. 2007; Medeiros et al. 2008). Improved understanding of the mechanisms driving cloud-climate feedbacks should help to reduce uncertainties in the parameterizations currently used in both global and regional climate models.

Cloud schemes in current regional and global climate models have to be highly parameterized because computational constraints do not allow for global cloudresolving models suitable for long integrations. Because of the nonlinearity of many cloud microphysical processes and the unresolved subgrid-scale variability of cloud properties and meteorological variables such as 
updraft velocity, cloud schemes are often empirically tuned to improve agreement with, for instance, observed top of the atmosphere (TOA) radiative fluxes (Bender 2008). Some recent efforts have addressed the problem of unresolved subgrid-scale cloud variability in largescale models by employing probability density functions (PDFs) for the description of cloud processes (e.g., Watanabe et al. 2009; Guo et al. 2010).

Direct implementation of parameterizations for precipitation formation processes such as autoconversion and accretion will result in a significant underestimation of precipitation production in large-scale models (e.g., Geoffroy et al. 2008; Larson et al. 2001; Pincus and Klein 2000; Rotstayn 2000; vanZanten et al. 2005; Wood 2000, 2005a,b; Wood et al. 2002; Yuan et al. 2006, and others). Similarly, this is also the case for many cumulus convection parameterizations commonly used in models with horizontal resolutions coarser than about $10 \mathrm{~km}$. For example Yang et al. (2011) investigate parameter tuning in the convection scheme in regional model simulations. The application of such parameter tuning may be problematic for application of cloud schemes in climate change scenarios in several ways (Pincus and Klein 2000). In particular, some parameterizations may be scale-dependent, that is, they need to be readjusted for each horizontal model resolution and may cease to work appropriately at some fine spatial resolution. Furthermore, it remains unclear whether an empirical tuning for present-day conditions is still valid for simulations of future climate.

The overall question of how limitations in the treatment of subgrid-scale cloud microphysical processes may affect the modeled sensitivity of climate has not been investigated very thoroughly thus far, although the recent work of Sanderson et al. (2008) suggests that the uncertainties in model cloud physics schemes can indeed have a substantial impact. They based their results on a very large "perturbed physics" ensemble with a global coupled model (climateprediction.net) and found, for example, that changing the rain accretion constant over a range of plausible values results in $\sim 25 \%$ change in simulated global climate sensitivity. A recent systematic approach of quantifying the uncertainty of the climate sensitivity is done within the Lawrence Livermore National Laboratory (LLNL) Climate Uncertainty Quantification (UQ) Project. In this project, perturbed parameter ensemble simulations are performed to investigate the impact of uncertain parameters in, for instance, shallow convection and cloud microphysics (C. Covey et al. 2011, unpublished manuscript).

In this study we attempt to address the uncertainties in modeling the response of low-level marine clouds to global warming that may be associated with the tuning of precipitation formation schemes. We do this by applying the new, observational constraint for precipitation formation from Bennartz et al. (2011), which not only eliminates the need of tuning the precipitation formation in warm clouds, but can also be applied at different horizontal model resolutions without adjustments or changes. Here, we focus on the East Pacific region with its two large and persistent stratocumulus decks, which are of particular importance for understanding cloud-climate feedbacks (Clement et al. 2009). The trade wind regime with its associated low-level clouds is the largest meteorological regime in the world. Trade wind cumuli are therefore also crucial to current climate as well as to estimates of climate change because they prevail over the global ocean (Stevens and Feingold 2009). In addition, the stratocumulus to trade cumulus transition might play a particularly important role in assessing and understanding cloud-climate feedbacks in projections of climate change. All of these cloud regimes are found over the East Pacific Ocean making it a region of particular interest for studying the sensitivity of lowlevel marine clouds to climate change.

Our study will make use of the International Pacific Research Center's Regional Atmospheric Model (iRAM). Lauer et al. $(2009,2010)$ have shown that this model can produce a rather realistic simulation of the cloud field over the East Pacific, at least when forced with observed boundary conditions. In particular, the iRAM cloud simulations are superior to those obtained with current global coupled climate models, which generally display significant deficiencies in representing low-level clouds in this region (Lauer et al. 2010). In the present work iRAM simulations are used to investigate the effects of treatment of the precipitation formation processes on modeled cloud climate feedbacks. In particular the simulated response of marine clouds over the East $\mathrm{Pa}$ cific to imposed global warming is compared in model experiments using the observational constraint for precipitation formation from Bennartz et al. (2011) (hereafter "integral constraint method") and using a conventional approach. The integral constraint method treats two important processes in warm clouds, autoconversion and accretion of cloud water, to form rain in a scale-independent way eliminating the need for empirical model tuning when running at different horizontal resolutions. Results from 1-yr integrations with this new method are analyzed and compared with the two conventional autoconversion parameterizations from Khairoutdinov and Kogan (2000) and Liu et al. (2007), which have not been empirically tuned for different horizontal model resolutions. A second set of model experiments compares the cloud-climate feedback obtained with the integral constraint method to results 
obtained with the conventional autoconversion scheme from Liu et al. (2007) as used in Lauer et al. (2010). Section 2 describes the regional climate model, the configuration, and model setup, as well as the implementation of the new rain formation method and the sets of model experiments performed. An analysis of the model integrations and comparisons with observations are given in section 3. Results for the cloud response to global warming at different horizontal resolutions and a comparison with results obtained with a conventional, tuned autoconversion scheme are discussed in section 4. Section 5 provides a summary of the main findings.

\section{Model and model simulations}

\section{a. The Regional Atmospheric Model}

Here, we use the International Pacific Research Center iRAM with double-moment cloud microphysics (Lauer et al. 2009, 2010). iRAM is a hydrostatic primitive equations model (Wang et al. 2004). The model has 28 vertical $\sigma$ levels with the top level at $10 \mathrm{hPa}$. The model simulations presented here were conducted at horizontal resolutions of $0.25^{\circ} \times 0.25^{\circ}, 0.5^{\circ} \times 0.5^{\circ}, 1^{\circ} \times 1^{\circ}$, and $2^{\circ} \times 2^{\circ}$ with the model domain covering the tropical and subtropical eastern Pacific as well as large parts of South America $\left(40^{\circ} \mathrm{S}-40^{\circ} \mathrm{N}\right.$ and $\left.170^{\circ}-50^{\circ} \mathrm{W}\right)$. Final analysis data (FNL) from the U.S. National Centers for Environmental Prediction (NCEP) are used as lateral boundary conditions and to initialize the model. Sea surface temperatures (SSTs) are prescribed from the National Oceanic and Atmospheric Administration (NOAA) optimum interpolation (OI) daily SST analysis (Reynolds et al.2007). A relaxation is applied to the model variables, including temperature, specific humidity, zonal and meridional wind components, and surface pressure within a $10^{\circ}$ buffer zone along the lateral boundaries. This buffer zone is excluded from the analyses presented below.

Grid-scale cloud processes are calculated using a double-moment cloud microphysics scheme with a prognostic treatment of six aerosol species inside clouds (Phillips et al. 2007, 2008, 2009). Aerosol activation in warm clouds is calculated using the scheme from Ming et al. (2006) (for details see Lauer et al. 2009). The treatment of warm rain formation by autoconversion of cloud droplets to rainwater and accretion of cloud water by raindrops has been changed from that in Lauer et al. (2010). Here, we use the method from Bennartz et al. (2011), which employs satellite observations to constrain the precipitation formation in warm clouds. This integral constraint method assumes that the subgrid-scale variability within a cloud field is dominated by variations in liquid water path (LWP) and that the horizontal
TABLE 1. The three scale-dependent parameters in the iRAM setup: the convective time scale $(\tau)$, the model time step $(\Delta t)$, and the LWP inhomogeneity parameter $g$ used for different horizontal resolutions [Eq. (1)]. Note that $g$ is only applied for the constrained experiments, whereas $\tau$ and $\Delta t$ are varied for all simulations.

\begin{tabular}{lcccc}
\hline & $0.25^{\circ} \times 0.25^{\circ}$ & $0.5^{\circ} \times 0.5^{\circ}$ & $1^{\circ} \times 1^{\circ}$ & $2^{\circ} \times 2^{\circ}$ \\
\hline$\tau$ & $1800 \mathrm{~s}$ & $3600 \mathrm{~s}$ & $7200 \mathrm{~s}$ & $10,800 \mathrm{~s}$ \\
$\Delta t$ & $360 \mathrm{~s}$ & $720 \mathrm{~s}$ & $1200 \mathrm{~s}$ & $1200 \mathrm{~s}$ \\
$g$ & 3.5 & 1.8 & 1.3 & 1.0 \\
\hline
\end{tabular}

subgrid-scale distribution of the liquid water path $(L)$ within a model grid box can be described with a gamma function:

$$
\operatorname{PDF}(L)=C \times L^{g-1} \exp \left(-\frac{g L}{\bar{L}}\right)
$$

Here, $g=\left(\bar{L} / \sigma_{L}\right)^{2}$ is an inhomogeneity parameter used for different horizontal resolutions, $\sigma_{L}$ is the scaledependent standard deviation of $L$ within a model grid box, $C$ is a normalization factor, and $\bar{L}$ is the gridbox average LWP. The standard deviation $\sigma_{L}$ and thus $g$ can be determined from satellite observations. A simple cloud model and the autoconversion and accretion parameterizations from Khairoutdinov and Kogan (2000) obtained from high-resolution large eddy simulations are used to calculate the precipitation formation of single clouds for given cloud temperature, cloud droplet number concentration, and liquid water path. These individual values are then integrated over the liquid water path PDF from satellite observations giving the cloud field-averaged precipitation generation (Bennartz et al. 2011). This is done for all horizontal model resolutions and model time steps investigated here (Table 1) and saved as lookup tables used for the model integrations to keep the additional computational burden to a minimum. A second change in the model configuration from that used in Lauer et al. (2010) is a reduction of the convective time scale (see Table 1). This change does not alter the model results very much, but does lead to a slight improvement in simulated convective precipitation in the intertropical convergence zone (ITCZ), which was overestimated in Lauer et al. (2010).

The integral constraint method gives the vertically integrated total precipitation generation averaged over a model grid box. However, to correctly account for all cloud microphysical processes, the model needs vertical profiles of autoconversion and accretion rates. To obtain those, the cloud microphysics calculations are called twice. The first call gives vertical profiles of autoconversion and accretion of cloud droplets to rain using the parameterization from Liu et al. (2007) 
but without changing any cloud properties as a result. Alternatively, we also tested the conventional autoconversion parameterization from Khairoutdinov and Kogan (2000). The differences in the results obtained with the integral constraint method using the Khairoutdinov and Kogan (2000) or Liu et al. (2007) as the underlying autoconversion schemes are very small. In the following, all results shown for the integral constraint method are obtained using Liu et al. (2007) as the underlying autoconversion scheme (Lauer et al. 2009, 2010).

The autoconversion and accretion rates from the original parameterizations are vertically integrated to obtain the total precipitation formation in a gridbox column. The vertical profiles of autoconversion and accretion are scaled by the ratio of the total precipitation formation given by the integral constraint method and the total precipitation formation from the original parameterizations. The scaled vertical profiles are then used for a second call to the cloud microphysics to determine the final values of cloud and rainwater. A schematic overview of the implementation of the integral constraint method into iRAM can be found in Bennartz et al. (2011), their Fig. 1. The total precipitation formation from the integral constraint method is taken from precalculated lookup tables using average cloud temperature, cloud droplet number concentration, and liquid water path as input parameters. Average cloud temperature and cloud droplet number are obtained by integrating vertically over the cloud using the ratio of total liquid water content at each model level to the total liquid water path of the cloud layer as integration weights. The integral constraint method in its current implementation is only valid for warm clouds. If the vertically integrated ice water content reaches $10 \%$ or more of the vertically integrated liquid water content, no scaling is performed and the original autoconversion/ accretion parameterizations are used instead. Over the tropical and subtropical East Pacific, this is particularly relevant in the ITCZ where deep convection occurs frequently.

All parameters and settings are kept the same at all horizontal resolutions except for the convective time scale in the convection scheme (Tiedtke 1989) as well as the model time step (Table 1). This adjustment of the convection scheme is necessary to account for scaledependent processes in the model, which are not directly related to the precipitation formation in warm clouds studied here. Additional details on the model and the cloud microphysics scheme can be found in Lauer et al. $(2009,2010)$ and the references therein. A model evaluation with data from aircraft, ships, and satellites focusing on clouds in the East Pacific region can also be found in Lauer et al. (2009), an evaluation of the seasonal cycle of cloud properties can be found in Wang et al. (2011).

\section{b. Evaluation and scaling model experiments}

The first set of model experiments discussed in section 3 covers the 1-yr period January through December 2006. This set of model experiments is used to evaluate the scale awareness of the integral constraint method by comparing model experiments at different horizontal resolutions with observations. Each of these model simulations is preceded by a 5-day spinup period for the model physics such as the planetary boundary layer and cloud processes, which is not included in the analysis below. We chose the year 2006 to be comparable to previous iRAM studies including the PreVOCA (PreVOCALS; see below) model intercomparison (Wyant et al. 2010).

We conduct several groups of model experiments at each horizontal resolution. Each group consists of four model experiments. The first of these four model experiments uses the original, untuned autoconversion parameterization from Liu et al. (2007), the second uses the original autoconversion formulation from Khairoutdinov and Kogan (2000). In this context, untuned refers to a nonmodified version of the parameterizations or a precipitation formation efficiency of unity. The third and fourth model simulations use the integral constraint method for the generation of precipitation in warm clouds from Bennartz et al. (2011), but applying Liu et al. (2007) and Khairoutdinov and Kogan (2000) (not shown) parameterizations, respectively, for the first call to the cloud microphysics scheme to determine the shape of the vertical profiles of rain formation rates. These experiments are used to assess the impact of the underlying autoconversion parameterization on the results obtained with the integral constraint method. At each horizontal resolution, the four model simulations of each group are otherwise identical. We compare these simulations with satellite observations and measurement data from the Variability of the American Monsoon Systems (VAMOS) Ocean-Cloud-Atmosphere-Land Study Regional Experiment (VOCALS-REx; Wood et al. 2011) and the Eastern Pacific Investigations of Climate 2001 field campaign (EPIC 2001; Raymond et al. 2004).

\section{c. Cloud feedback model experiments}

A second set of model experiments has been conducted to analyze the impact of model tuning on results for the cloud response to imposed global warming. Results with the integral constraint method are compared with those obtained with the conventional autoconversion 
parameterization from Liu et al. (2007) but otherwise identical model setup. For each of the two autoconversion schemes two kinds of experiments are performed: 1) a present-day simulation covering the 10 -yr period January 1999 through December 2008 using observed SSTs and lateral boundary conditions and 2) a 10-yr simulation representing late twenty-first century conditions. The present-day simulation uses monthly mean $\mathrm{CO}_{2}$ concentrations measured at the Mauna Loa Observatory, Hawaii. The $\mathrm{CO}_{2}$ data are available from the NOAA Earth System Research Laboratory (ESRL, http://www.ersl.noaa.gov/). The global warming simulations use a fixed $\mathrm{CO}_{2}$ concentration of $720 \mathrm{ppm}$. As in Lauer et al. (2010), we apply the pseudo-global-warming method (Kimura and Kitoh 2007; Sato et al. 2007; Knutsen et al. 2008) to downscale climate change projections from global models using the iRAM. In the pseudo-global-warming method, lateral boundary conditions are given by the sum of the 6-hourly reanalysis data and observed SSTs used in the present-day simulation and a climate change signal added as a perturbation. The climate change signal is obtained from monthly mean differences between present-day (199099) simulations and projections for the end of the twenty-first century (2090-99) from the global climate models included in the Intergovernmental Panel on Climate Change (IPCC) Fourth Assessment Report (AR4). The climate change signal used here is calculated from the differences in 10 -yr means for each calendar month obtained from an ensemble of 19 climate models for the Special Report on Emissions Scenarios (SRES) A1B simulations. The climate model data are available from the World Climate Research Programme's (WCRP's) Model Intercomparison Project phase 3 (CMIP3) archive (Meehl et al. 2007). A list of the global models used with references and more details on the calculation of the climate change signals can be found in Lauer et al. (2010), their Table 1. The cloud feedback model experiments presented in section 4 are conducted at horizontal resolutions of $0.5^{\circ} \times 0.5^{\circ}, 1^{\circ} \times$ $1^{\circ}$, and $2^{\circ} \times 2^{\circ}$. The decade-long integrations to assess the cloud-climate feedback at a horizontal resolution of $0.25^{\circ} \times 0.25^{\circ}$ exceed our computational resources and could therefore not be included.

\section{Present-day results}

\section{a. Precipitation rates at cloud base}

The resolution of climate models suitable for long integrations needed for addressing climate-related questions is too coarse to resolve clouds, which are usually on the order of one to a few kilometers in their horizontal scales. A common approach to deal with the unresolved subgrid-scale variability of cloud variables to obtain improved agreement of modeled cloud properties with observations is to change the precipitation formation efficiency of warm clouds. In this method, the autoconversion rate is usually multiplied by a constant factor or the threshold value for the onset of precipitation formation is lowered to implicitly compensate for the neglected subgrid-scale variability. The compensation required increases with decreasing horizontal model resolution, that is, the correction is small for high-resolution models and large for coarse-resolution models such as $1^{\circ} \times 1^{\circ}$ and coarser.

Figure 1 shows an intercomparison of the precipitation rates at cloud base obtained with the conventional autoconversion schemes from Liu et al. (2007) and Khairoutdinov and Kogan (2000) as well as from the integral constraint method for an idealized cloud. The cloud liquid water content $q_{c}$ is assumed to increase vertically linearly above cloud base with $q_{c}(z)=f_{\text {sub }} c_{w} z$. Here, $z$ is the height above cloud base, $c_{w}$ is the condensation rate, and $f_{\text {sub }}$ is a subadiabaticity factor as defined by Wood et al. (2009): $f_{\text {sub }}=z_{0} /\left(z_{0}+z\right)$ with $z_{0}=500 \mathrm{~m}$. The average cloud temperature is assumed to be $280 \mathrm{~K}$. The results shown for the conventional autoconversion schemes have been obtained with the original, untuned parameterizations. The rain formation rates shown for the integral constraint method are calculated for a $0.5^{\circ} \times 0.5^{\circ}$ grid resolution, that is, an inhomogeneity parameter $g=1.8$ [Eq. (1)] and a time step of $720 \mathrm{~s}$ (see Table 1). The differences in precipitation rates using the different autoconversion schemes can be large. Low-level marine clouds usually have small liquid water path values and low droplet number concentrations. For such thin clouds (LWP $<0.2 \mathrm{~kg} \mathrm{~m}^{-2}, N<$ $100 \mathrm{~cm}^{-3}$ ), the integral constraint method gives between $50 \%$ and $100 \%$ higher precipitation rates at cloud base than the original Khairoutdinov and Kogan (2000) parameterization. Since the integral constraint method applies the same autoconversion parameterization to individual clouds (Bennartz et al. 2011), these differences result only from accounting for the subgrid-scale variability of clouds in a typical $0.5^{\circ} \times 0.5^{\circ}$ grid cell. In contrast, the Liu et al. (2007) scheme produces even higher precipitation rates at cloud base, rates that can be a factor of 5-10 higher than those obtained with the Khairoutdinov and Kogan (2000) parameterization. Differences among precipitation rates from different autoconversion schemes are even larger for thick clouds with a liquid water path larger than $0.5 \mathrm{~kg} \mathrm{~m}^{-2}$ underlining the very significant uncertainties associated with precipitation formation in warm clouds in climate models. 
Liu et al. (2007)

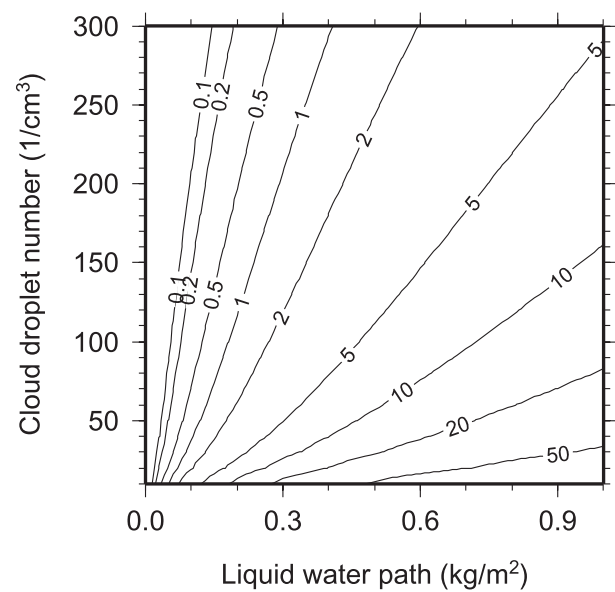

Khairoutdinov and Kogan (2000)

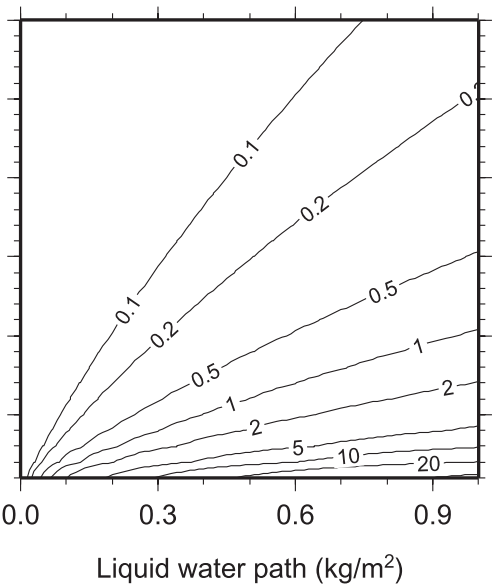

Integral constraint method

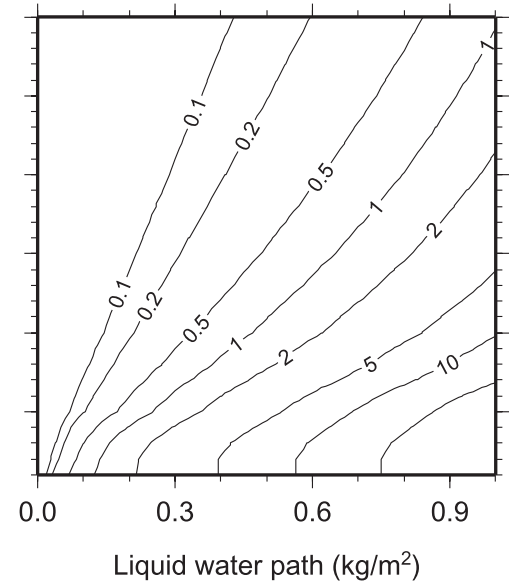

FIG. 1. Rain rates at cloud base in $\mathrm{mm} \mathrm{day}^{-1}$ as a function of liquid water path $\left(\mathrm{kg} \mathrm{m}^{-2}\right)$ and cloud droplet number concentration $\left(\mathrm{cm}^{-3}\right)$ for a cloud with vertically linearly increasing liquid water content and an average temperature of $280 \mathrm{~K}$ (for details see text). Shown are the results from the autoconversion schemes of (left) Liu et al. (2007), (middle) Khairoutdinov and Kogan (2000), and (right) the integral constraint method. The integral constraint method assumes a grid cell size of $0.5^{\circ} \times 0.5^{\circ}[\mathrm{g}=1.8$, Eq. (1) $]$ and a time step of $720 \mathrm{~s}$.

\section{b. Liquid water path}

The effect of differences in autoconversion schemes becomes more clearly evident in the simulated LWP averages. For example, Fig. 2 shows the 3 -month mean LWP (September, October, November 2006) from iRAM obtained with the three different autoconversion schemes at horizontal resolutions between $0.25^{\circ} \times$ $0.25^{\circ}$ and $2^{\circ} \times 2^{\circ}$ in comparison with the University of Wisconsin observational analysis for the same period (UWisc). The UWisc analysis is based on satellite observations of the Special Sensor Microwave Imager (SSM/ I), the Tropical Rainfall Measuring Mission (TRMM) Microwave Imager (TMI), and the Advanced Microwave Scanning Radiometer (AMSR-E) (O'Dell et al. 2008). The satellite observations show an average LWP in the core regions of the two stratocumulus decks off the coasts of North and South America in the range of $100 \mathrm{~g} \mathrm{~m}^{-2}$ and in the ITCZ region values between 200 and $250 \mathrm{~g} \mathrm{~m}^{-2}$. Minimum LWP values are found south of the ITCZ between the equator and $10^{\circ} \mathrm{S}$ and $160^{\circ}$ and $100^{\circ} \mathrm{W}$. This basic geographical pattern is reproduced by iRAM reasonably well, but LWP is overestimated in the simulations using the Khairoutdinov and Kogan (2000) parameterization particularly in the stratocumulus regions. This overestimation ranges between $20 \%$ and $30 \%$ at $0.25^{\circ} \times 0.25^{\circ}$ resolution and up to $100 \%$ at a horizontal resolution of $2^{\circ} \times 2^{\circ}$. This strongly suggests that the precipitation formation, which is an important sink process for cloud liquid water, is too weak and thus cloud lifetime is too long. As discussed above, this overestimation results from the use of gridbox averages as input for the autoconversion scheme thereby neglecting the subgrid-scale variabilities of cloud properties such as liquid water content. As expected, this effect becomes stronger for coarser horizontal resolutions. Similarly, the model experiments using the original Liu et al. (2007) parameterization overestimate LWP at $1^{\circ} \times$ $1^{\circ}$ and particularly at $2^{\circ} \times 2^{\circ}$ by up to $40 \%$. At $0.5^{\circ} \times 0.5^{\circ}$, the Liu et al. (2007) autoconversion provides LWP values in the stratocumulus regions, which are closest to the observed ones around $100 \mathrm{~g} \mathrm{~m}^{-2}$. For this reason, Liu et al. (2007) was chosen in our previous model studies (Lauer et al. 2009, 2010). When going to a horizontal resolution of $0.25^{\circ} \times 0.25^{\circ}$, the average LWP is underestimated using Liu et al. (2007). This suggests that the Liu et al. (2007) autoconversion parameterization can be used at $0.5^{\circ} \times 0.5^{\circ}$ but has to be corrected for subgrid-scale processes at all other horizontal resolutions. In contrast, the integral constraint method delivers LWP values in the stratocumulus regions close to the observations of around $100 \mathrm{~g} \mathrm{~m}^{-2}$ at all horizontal resolutions tested here from $0.25^{\circ} \times 0.25^{\circ}$ through $2^{\circ} \times$ $2^{\circ}$. This suggests that the integral constraint method can be successfully applied to eliminate autoconversion efficiency as a tuning parameter and avoid otherwise necessary adjustments when changing the horizontal model resolution. This makes the integral constraint method a good tool to investigate the impact of autoconversion tuning on the results for the cloud response to global warming.

Figure 3 shows the 3-month average (September, October, November 2006) scaling factors applied to the autoconversion rates from Liu et al. (2007) and the 


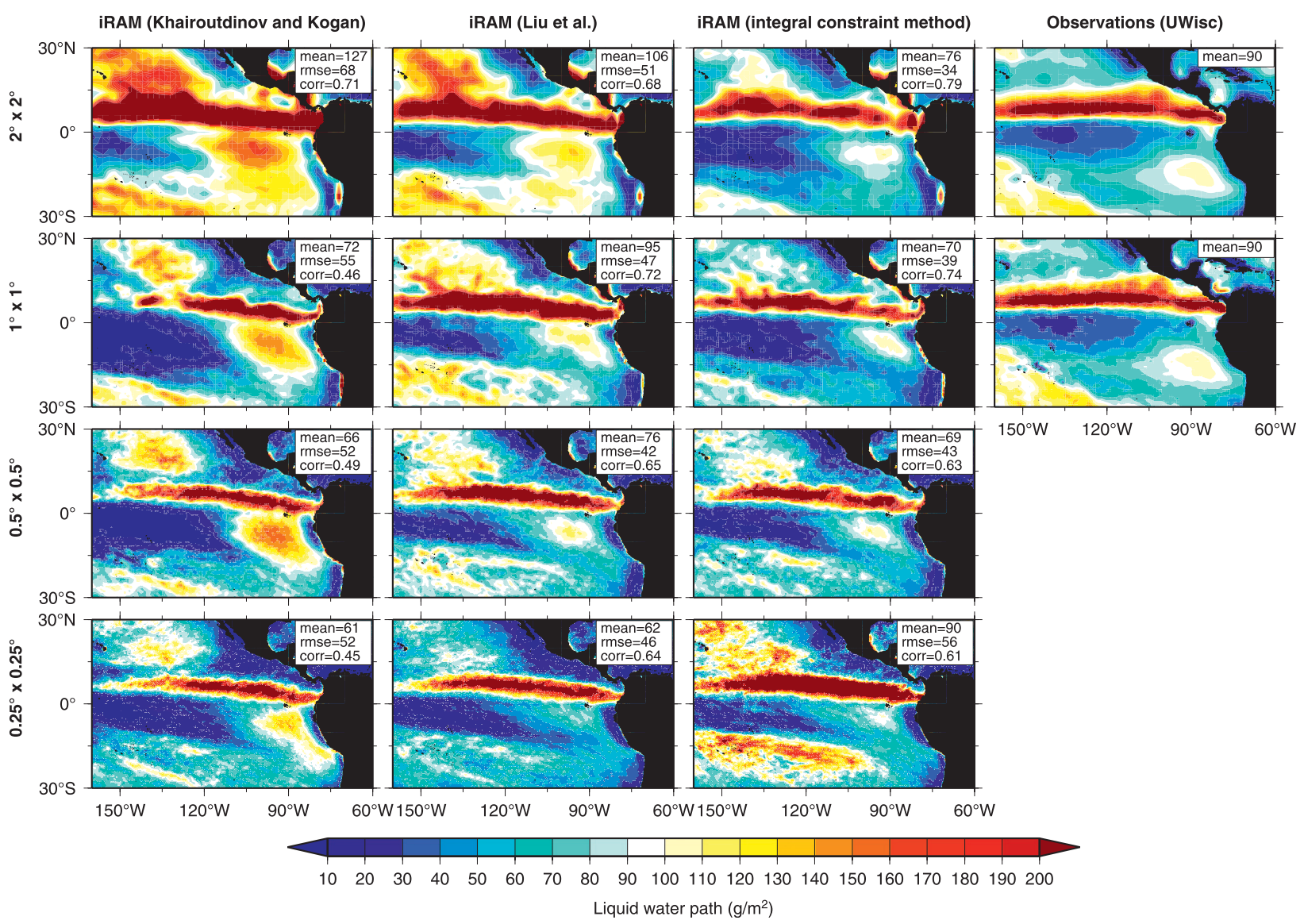

FIG. 2. September-October-November 2006 average of the liquid water path $\left(\mathrm{g} \mathrm{m}^{-2}\right)$ from iRAM with the original Khairoutdinov and Kogan (2000) autoconversion scheme, the original Liu et al. (2007) scheme and with the integral constraint method compared with satellite observations from the University of Wisconsin climatology (UWisc) based on SSM/I, TMI, and AMSR-E (O'Dell et al. 2008). Shown are the horizontal resolutions (top to bottom) $2^{\circ} \times 2^{\circ}, 1^{\circ} \times 1^{\circ}, 0.5^{\circ} \times 0.5^{\circ}$, and $0.25^{\circ} \times 0.25^{\circ}$.

accretions rates in the simulations with the integral constraint method shown in Fig. 2 (third column). The scaling factors are highest in the $2^{\circ} \times 2^{\circ}$ simulation and decrease monotonically when going to higher resolutions as more and more of the cloud variability is being resolved explicitly by the model. The corresponding scaling factors for the Khairoutdinov and Kogan (2000) parameterization (not shown) are about a factor of five higher over a wide range of liquid water path/cloud droplet number concentration values because their rain formation rates are much smaller than those from Liu et al. (2007) (see Fig. 1).

The differences in the LWP results obtained with the three autoconversion schemes are smallest at the highest horizontal model resolution. This can also be seen in the probability density functions (PDFs) of daily-mean LWP depicted in Fig. 4. The PDFs have been calculated using daily-mean data from January through December 2006 for all grid cells over the ocean. iRAM overestimates the frequency of occurrence when using the
Khairoutdinov and Kogan (2000) autoconversion particularly for clouds with a LWP larger than $120 \mathrm{~g} \mathrm{~m}^{-2}$ while underestimating thinner clouds. The agreement with observations gradually improves when going to finer horizontal resolutions. Without taking into account the subgrid-scale variability of the cloud properties, iRAM using the Khairoutdinov and Kogan (2000) autoconversion underestimates the precipitation formation resulting in an unrealistically long cloud lifetime and subsequent overestimation of the cloud liquid water content. In contrast, the much higher precipitation formation rates from the Liu et al. (2007) scheme partly compensate for neglecting subgrid-scale variabilities and give results that are in better agreement with observations, particularly at $1^{\circ} \times 1^{\circ}$ and $2^{\circ} \times 2^{\circ}$ than those obtained with the Khairoutdinov and Kogan (2000) scheme. Over a wide range of LWP values (30-250 $\mathrm{g} \mathrm{m}^{-2}$ ) the integral constraint method provides consistent results among all horizontal resolutions tested and reasonably good agreement with the satellite observations. 

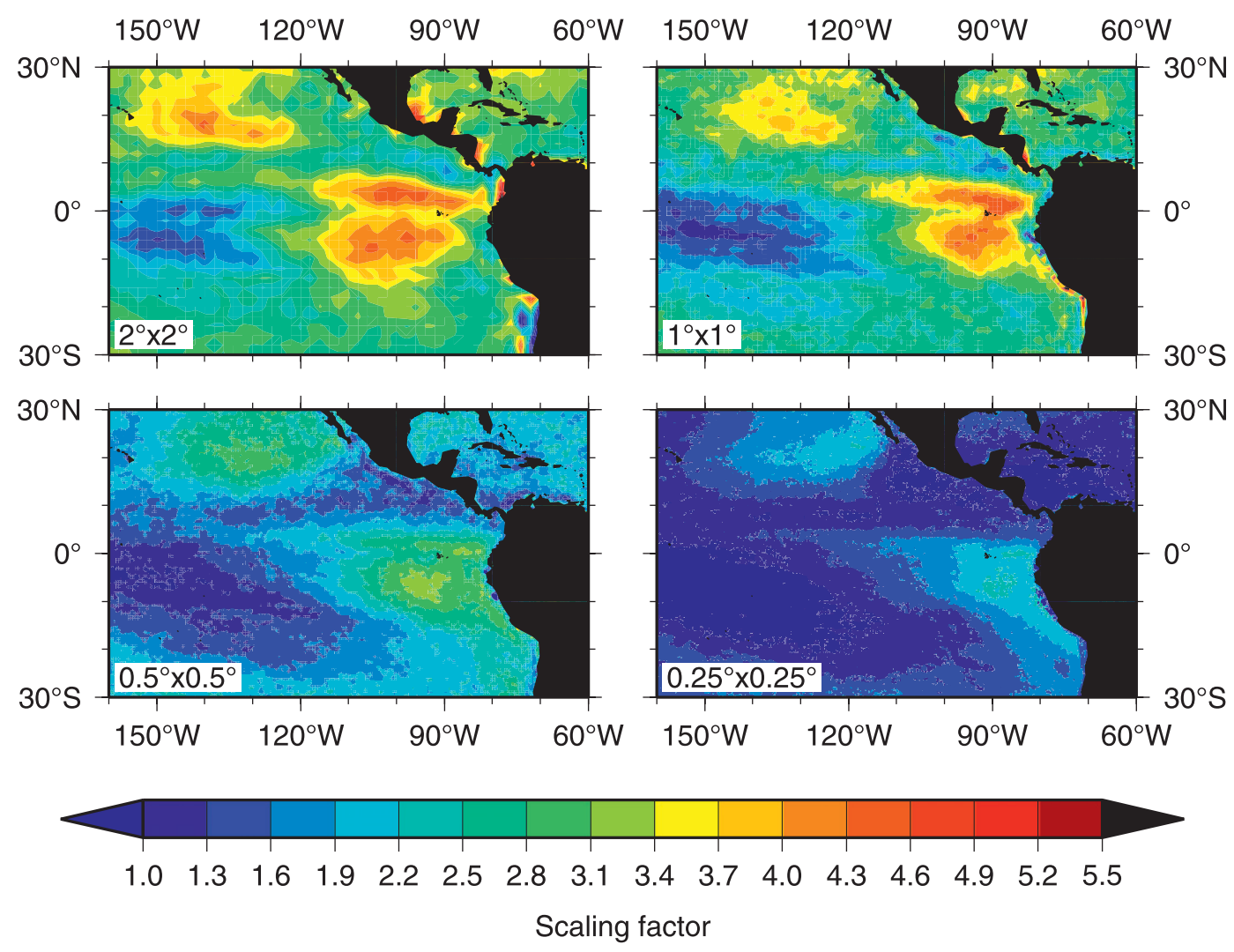

FIG. 3. September-October-November 2006 average of the scaling factors applied by the integral constraint method to the autoconversion rates from Liu et al. (2007). Shown are the horizontal resolutions (top to bottom) $2^{\circ} \times$ $2^{\circ}, 1^{\circ} \times 1^{\circ}, 0.5^{\circ} \times 0.5^{\circ}$, and $0.25^{\circ} \times 0.25^{\circ}$.

The only exception is for very thin clouds (LWP < $30 \mathrm{~g} \mathrm{~m}^{-2}$ ) at the coarsest horizontal resolution, whose simulated frequency of occurrence is smaller at $2^{\circ} \times 2^{\circ}$ than at all other horizontal resolutions. Because this is not only the case for the model simulations using the integral constraint method but similarly for the two conventional autoconversion schemes, this is likely caused by differences in scale-dependent processes due to unresolved subgrid-scale variability other than warm rain formation.

\section{c. Vertical profile of cloud liquid water}

LWP is a key quantity determining the clouds' effect on TOA radiative fluxes and thus the cloud contribution to the global energy balance. For cloud microphysical processes the vertical distribution of cloud liquid water is also highly relevant. Figure 5 shows a comparison of the vertical cloud liquid water profile from iRAM with aircraft observations taken during the field experiments VOCALS-REx and EPIC 2001. The VOCALS-REx data are the "National Center for Atmospheric Research (NCAR)/National Science Foundation (NSF) C-130 Navigation, State Parameter, and Microphysics Low-Rate
(LRT) data" provided by NCAR/Earth Observing Laboratory (EOL) under sponsorship of the National Science Foundation (http://data.eol.ucar.edu/). We averaged all 14 VOCALS-REx flights covering the region $85^{\circ}-74^{\circ} \mathrm{W}, 29^{\circ}-17^{\circ} \mathrm{S}$ taken in October and November 2008. The EPIC data "NSF/NCAR EC-130Q Hercules (N130AR)" are averaged over 19 flights in the region $97^{\circ}-94^{\circ} \mathrm{W}, 5^{\circ} \mathrm{N}-16^{\circ} \mathrm{N}$ conducted in September and October 2001. The dataset is also available from NCAR/ EOL (http://www.eol.ucar.edu/raf/Projects/EPIC2001/). For comparison with the model data, the aircraft data have been binned to a $0.5^{\circ} \times 0.5^{\circ}$ grid and 25- (VOCALSREx) and 50-hPa (EPIC 2001) layers. The model data are monthly means for October and November (VOCALSREx) and September and October (EPIC 2001) averaged over the domains covered by the measurement flights. The model experiments shown applied the Liu et al. (2007) autoconversion scheme and the integral constraint method at horizontal resolutions from $0.25^{\circ} \times 0.25^{\circ}$ to $2^{\circ} \times 2^{\circ}$. All model and observational data are conditionally averaged over cloudy situations by applying a threshold of $0.025 \mathrm{~g} \mathrm{~kg}^{-1}$ for the minimum cloud liquid water content. 

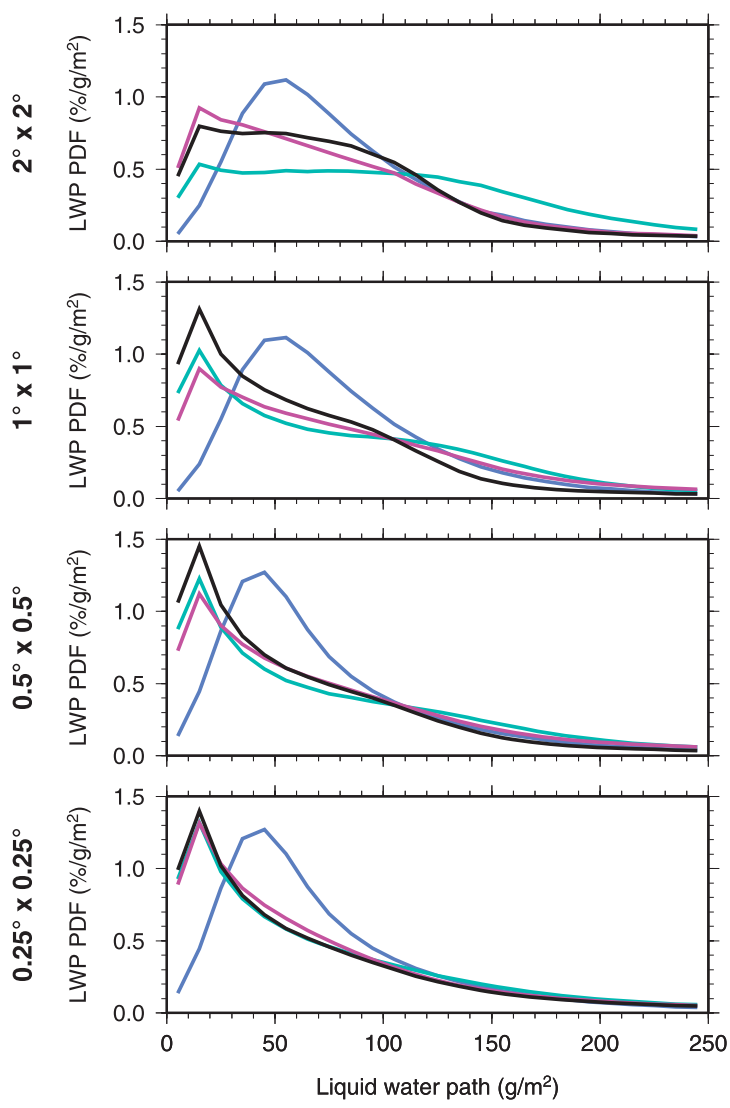

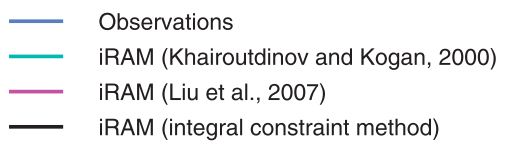

FIG. 4. PDFs of daily-mean LWP over the ocean from satellite observations (UWisc, O'Dell et al. 2008) in comparison with iRAM model results. The satellite data have a resolution of $0.5^{\circ} \times 0.5^{\circ}$ and have been regridded to the corresponding model grid.
Stratocumulus clouds are very frequent and represent the dominant cloud type in the subtropical Southeast Pacific region covered by the VOCALS-REx measurements. The domain-averaged model results in this region obtained with both autoconversion schemes are very close to each other in the boundary layer between the surface and $900 \mathrm{hPa}$ at all tested horizontal resolutions. The observed liquid water content in the boundary layer is very small. The model systematically overestimates the average liquid water content in the boundary layer. Above $900 \mathrm{hPa}$, model simulations and observations agree reasonably well within the measurement uncertainties estimated by the temporal and spatial variability of the observations (Fig. 5). At a horizontal resolution of $0.5^{\circ} \times 0.5^{\circ}$, the model results obtained with the Liu et al. (2007) scheme and with the integral constraint method are almost identical confirming that the systematically higher precipitation formation rates of the Liu et al. (2007) autoconversion scheme compared with Khairoutdinov and Kogan (2000) implicitly account for the neglected subgrid-scale variability at this horizontal resolution. At higher horizontal resolutions $\left(0.25^{\circ} \times 0.25^{\circ}\right)$, the model experiment using Liu et al. (2007) produces smaller liquid water content values than that using the integral constraint method.
This is consistent with smaller than observed LWP values in the Southeast Pacific stratocumulus deck from the Liu et al. (2007) scheme as seen in Fig. 2.

The EPIC measurements cover the ITCZ region over the tropical East Pacific between $5^{\circ} \mathrm{N}$ and $16^{\circ} \mathrm{N}$ with frequent deep convection. In contrast to the stratocumulus case of VOCALS-REx, no clear advantage or disadvantage can be seen for any specific autoconversion scheme. All modeled liquid water profiles are in reasonably good agreement with the observations, particularly given the large variability of the measurements shown in Fig. 5. This suggests that in case of frequent deep convection, the convection scheme plays an important role in determining the cloud liquid water profile whereas the microphysics are very important for thin stratiform clouds.

\section{d. Shortwave cloud forcing}

We calculate the shortwave cloud forcing (SCF) as the difference between the all-sky and clear-sky shortwave radiation at the TOA. Figure 6 shows a comparison of the annual mean SCF from iRAM calculated for horizontal resolutions between $0.25^{\circ} \times 0.25^{\circ}$ and $2^{\circ} \times 2^{\circ}$ using the three different autoconversion schemes with satellite observations. The satellite data are taken from 
VOCALS-REX

$\left(85^{\circ} \mathrm{W}-74^{\circ} \mathrm{W}, 29^{\circ} \mathrm{S}-17^{\circ} \mathrm{S}\right)$

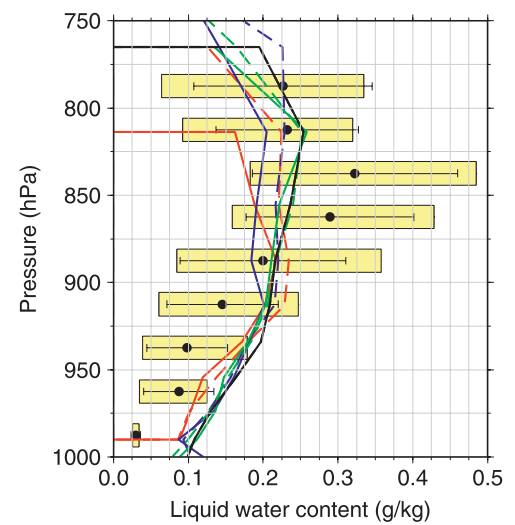

EPIC 2001

$\left(97^{\circ} \mathrm{W}-94^{\circ} \mathrm{W}, 5^{\circ} \mathrm{N}-16^{\circ} \mathrm{N}\right)$

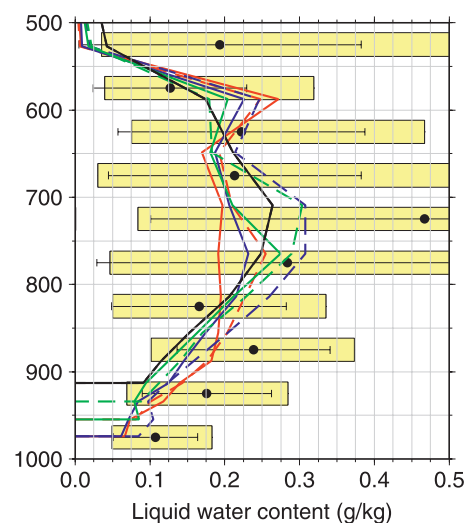

$-\operatorname{iRAM}\left(2^{\circ} \times 2^{\circ}\right)$

$-\operatorname{iRAM}\left(1^{\circ} \times 1^{\circ}\right)$

$-\operatorname{iRAM}\left(0.5^{\circ} \times 0.5^{\circ}\right)$

iRAM $\left(0.25^{\circ} \times 0.25^{\circ}\right)$

$\longmapsto$ observations mean+std.dev

$\square$ observations median+10/90-percentiles

FIG. 5. Vertical profiles of cloud liquid water content from aircraft measurements during (left) the VOCALS-REx field campaign (Wood et al. 2011) and (right) EPIC 2001 (Raymond et al. 2004) in comparison with iRAM model results. Dashed lines show model results with the original Liu et al. (2007) scheme, solid lines with the integral constraint method. The aircraft data have been binned to a $0.5^{\circ} \times 0.5^{\circ}$ grid and 25- (VOCALS-REx) and 50-hPa (EPIC 2001) layers.

the Clouds and the Earth's Radiant Energy System (CERES) Energy Balanced and Filled (EBAF) dataset (Wielicki et al. 1996; Loeb et al. 2009). The observations show SCF values around -80 to $-100 \mathrm{~W} \mathrm{~m}^{-2}$ in the two stratocumulus regions as well as in the ITCZ. The observed magnitude of the SCF is small south of the ITCZ and between the western model domain boundary at $160^{\circ} \mathrm{W}$ and about $100^{\circ} \mathrm{W}$. These small values result particularly from typically low average cloud amounts in this region. This basic geographical pattern is reproduced by the model. The SCF amplitude, however, differs significantly among the tested horizontal resolutions and autoconversion schemes. The integral constraint method provides consistent SCF results at resolutions $0.25^{\circ} \times 0.25^{\circ}$ to $1^{\circ} \times 1^{\circ}$ in reasonably good agreement with the CERES observations. At a horizontal resolution of $2^{\circ} \times 2^{\circ}$, SCF is overestimated by up to $50 \%$ in the ITCZ and off the coast of Central America in particular. Using the conventional autoconversion schemes from Liu et al. (2007) and Khairoutdinov and Kogan (2000), only the highest horizontal resolutions of $0.25^{\circ} \times 0.25^{\circ}$ and $0.5^{\circ} \times 0.5^{\circ}$ provide reasonably good agreement with observed SCF. The coarser-resolution simulations at $1^{\circ} \times 1^{\circ}$ and $2^{\circ} \times 2^{\circ}$ in particular strongly overestimate SCF throughout the model domain. This is a result of the overestimation in cloud amount and cloud liquid water caused by a too low precipitation formation rate, which can also be seen in the LWP (Fig. 2).

\section{Cloud-climate feedbacks}

To investigate the uncertainties in modeling the response of low-level marine clouds to global warming associated with the tuning of precipitation formation schemes, we compare results for the cloud response to global warming obtained with the observational constraint for precipitation formation from Bennartz et al. (2011), which does not need to be tuned at different horizontal resolutions, with results obtained with the conventionally tuned autoconversion parameterization from Liu et al. (2007). Similar to conventional tuning it is unclear at this point whether present-day constraints from observations are applicable for future climate. This uncertainty in modeling the cloud response to global warming is not reduced with the integral constraint method.

The response of clouds over the East Pacific to climate change is estimated by analyzing the differences in 10-yr means of cloud amount, LWP, and cloud radiative forcing between a global warming and a corresponding present-day simulation. The sensitivity of clouds to changes in surface temperature is quantified using the local cloud-climate feedback parameter $\lambda$. The parameter $\lambda$ is calculated from changes in net cloud radiative forcing $\left(\mathrm{CF}_{\text {net }}\right)$, which is defined as the sum of shortwave and longwave cloud forcing and changes in surface temperature $\left(T_{s}\right)$ :

$$
\lambda=\frac{\Delta \mathrm{CF}_{\text {net }}}{\Delta T_{s}} .
$$

This definition of $\lambda$ is widely used to diagnose climate simulations because of its simplicity and because cloud forcing defined as difference between all-sky and clear-sky radiation at the TOA can be estimated from observations (Bony et al. 2006). Negative values of $\lambda$ correspond 
iRAM (Khairoutdinov and Kogan)
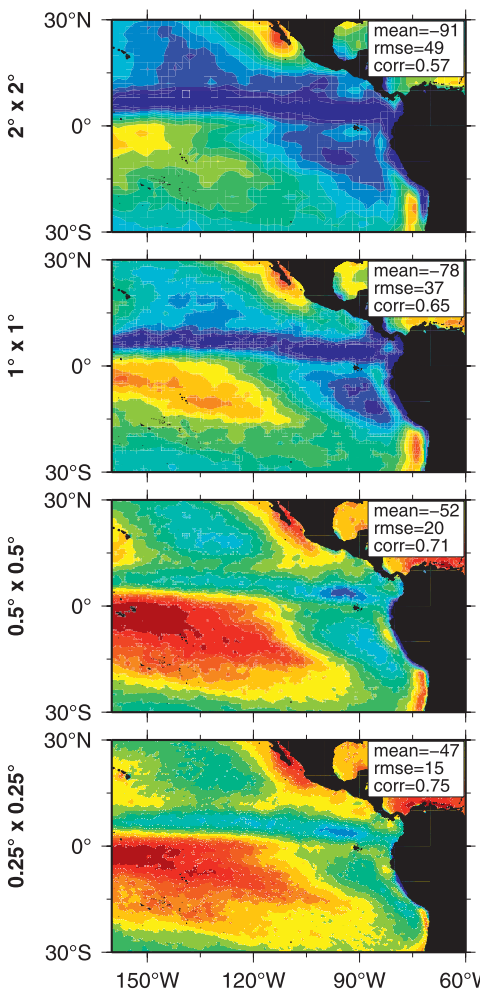

iRAM (Liu et al.)
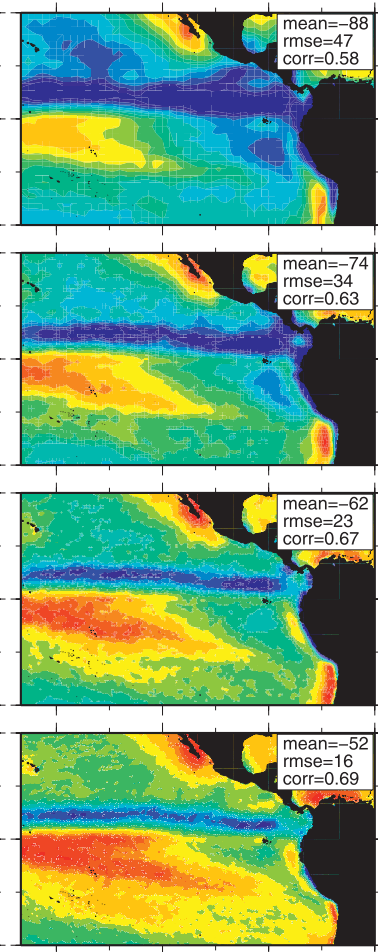

iRAM (integral constraint method)
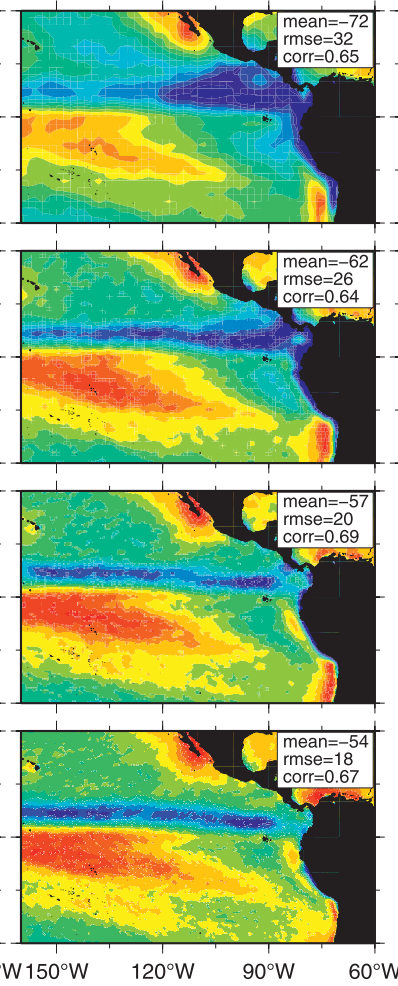

Observations (CERES EBAF)
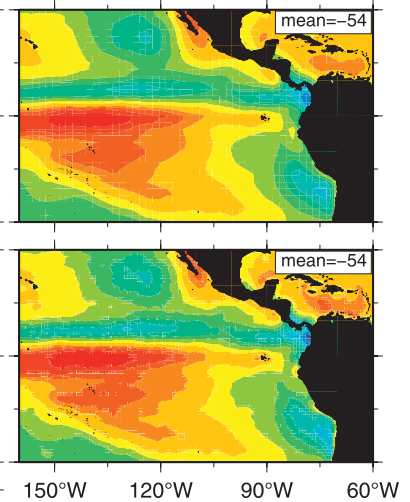

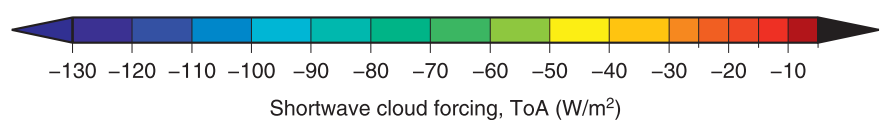

FIG. 6. Annual average shortwave (solar spectral range) cloud forcing at the top of the atmosphere (TOA) in W $\mathrm{m}^{-2}$ : (left to right) iRAM simulation with the original Khairoutdinov and Kogan (2000) autoconversion scheme, the original Liu et al. (2007) scheme, and the integral constraint method in comparison with (right) Clouds and the Earth's Radiant Energy System (CERES) satellite observations (Loeb et al. 2009).

to an increase in radiative cooling by clouds, positive values correspond to less cooling/increased warming by clouds as a response to increased surface temperatures.

\section{a. Changes in cloud amount and local feedback parameters}

Figure 7 shows changes in the annual mean low-level cloud amount (i.e., clouds below $700 \mathrm{hPa}$ ) and the local cloud feedback parameter $\lambda$ obtained with the two autoconversion schemes at a horizontal resolution of $0.5^{\circ} \times 0.5^{\circ}$. The underlying climate change signal for sea surface temperatures obtained from CMIP3 results for late twenty-first century conditions (see section $2 \mathrm{c}$ for details) is also shown. Both autoconversion schemes give a very similar geographical pattern and amplitude for changes in the low-level cloud amount because of global warming and the corresponding local feedback parameters. Simulations with the conventional autoconversion scheme as well as with the integral constraint method show a distinct reduction in low-level cloud amount by $5 \%-10 \%$ particularly in the two stratocumulus regions in the Northeast $\left(120^{\circ}-140^{\circ} \mathrm{W}, 15^{\circ}-\right.$ $\left.30^{\circ} \mathrm{N}\right)$ and Southeast Pacific $\left(82^{\circ}-96^{\circ} \mathrm{W}, 15^{\circ}-5^{\circ} \mathrm{S}\right)$. Average liquid water path values in these regions also decrease by about $10 \%$. The corresponding local feedback parameters in the stratocumulus regions are in the range of $4-7 \mathrm{~W} \mathrm{~m}^{-2} \mathrm{~K}^{-1}$. As discussed in Lauer et al. (2010), this positive cloud-climate feedback simulated by iRAM in the stratocumulus regions is particularly caused by a decrease in low-level cloud amount. This decrease in low-level cloud amount in the model is a result of the decrease in average inversion height. The temperature inversion in the subtropical subsidence regions caps the marine boundary layer clouds and prevents further vertical growth of the stratocumuli. With an average inversion height decrease and only a marginal average cloud base height change, the mean cloud thickness decreases. This makes the stratocumulus decks more susceptible to breaking up and reduces the average cloud amount (Lauer et al. 2010). In contrast, low-level 
(A)

conventional autoconversion
(B)

integral constraint method
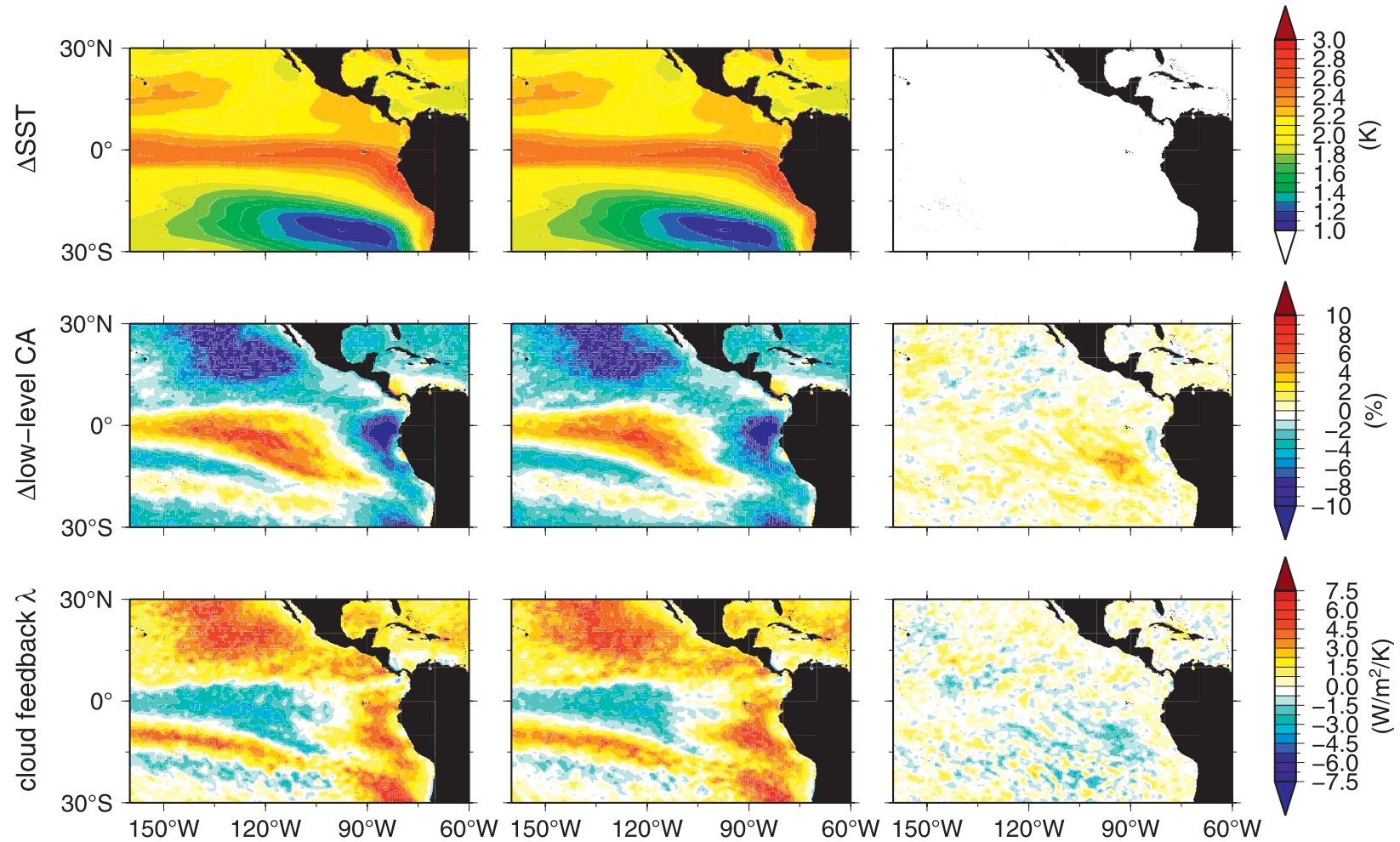

FIG. 7. Ten-year average change in (middle) low-level cloud amount ( $\Delta \mathrm{CA})$, (bottom) cloud feedback parameter $(\lambda)$, and (top) the underlying climate change signal in sea surface temperatures ( $\Delta$ SST, top) due to global warming compared with present-day conditions. (left) (a) The results from the conventional autoconversion scheme (Liu et al. 2007), (middle) (b) the results from the integral constraint method, and (right) shows the differences between (a) and (b).

cloud amount increases by $2 \%-8 \%$ in the equatorial Pacific region resulting in negative local cloud feedback parameters of around -2 to $-3 \mathrm{~W} \mathrm{~m}^{-2} \mathrm{~K}^{-1}$. The equatorial Pacific is the only region in the East Pacific showing a significant negative cloud-climate feedback. This negative cloud-climate feedback in the model is caused by an increased low-level cloud amount as a result of increased low-level convergence. The increased low-level convergence itself is a response to the stronger increase in equatorial SSTs compared to adjacent regions to the north and south (Fig. 7). For a more detailed discussion on possible mechanisms of the modeled cloud-climate response in the East Pacific we refer to our previous work in Lauer et al. (2010).

Throughout most of the model domain, differences in the local feedback parameters obtained with the two autoconversion schemes are small and within a range of -1 and $1 \mathrm{~W} \mathrm{~m}^{-2} \mathrm{~K}^{-1}$. Clouds in the model simulation with the integral constraint method are, however, slightly more sensitive to global warming yielding local feedback parameters at individual locations that can be up to $1-3 \mathrm{~W} \mathrm{~m}^{-2} \mathrm{~K}^{-1}$ higher than those obtained with the conventional autoconversion scheme: At a horizontal resolution of $0.5^{\circ} \times 0.5^{\circ}$, application of the integral constraint method results in a slightly increased sensitivity of low-level marine clouds to global warming throughout the model domain with exception of the Northeast Pacific stratocumulus region and the equatorial region $\left(115^{\circ}-145^{\circ} \mathrm{W}, 4^{\circ} \mathrm{S}-4^{\circ} \mathrm{N}\right)$. The average cloud sensitivity increases by $9 \%$ in the two trade wind regions and by $31 \%$ in the Southeast Pacific stratocumulus region. In contrast, the sensitivities decrease by $2 \%$ in the Northeast Pacific stratocumulus region and by $11 \%$ in the equatorial Pacific. Averaged over the whole model domain, the cloud sensitivity to global warming increases by $15 \%$ when applying the integral constraint method compared with that applying the conventional approach. The model results suggest that uncertainties in estimates of the cloud-climate feedback of low marine clouds over the East Pacific introduced by tuning the warm rain formation to compensate for subgrid-scale variabilities of cloud properties are small. However, we would like to stress that this does not necessarily apply to mid- and high-level clouds. The regional model 


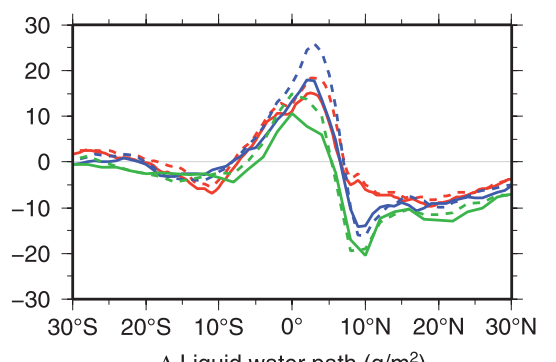

$\Delta$ Liquid water path $\left(\mathrm{g} / \mathrm{m}^{2}\right)$

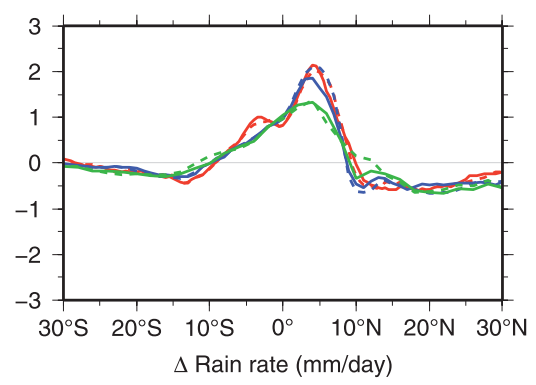

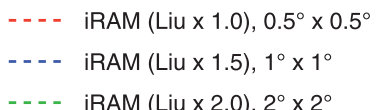

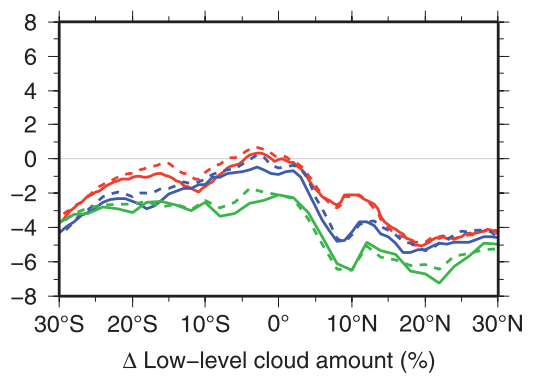

$\Delta$ Low-level cloud amount (\%)

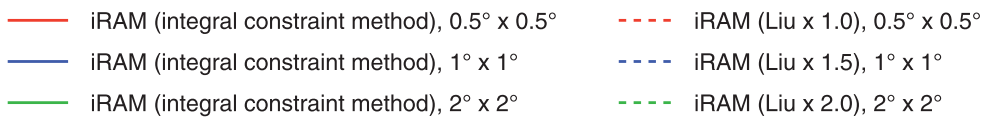

FIG. 8. 10-yr mean changes in zonally averaged $\left(160^{\circ}-60^{\circ} \mathrm{W}\right)$ (left) liquid water path (in $\left.\mathrm{g} \mathrm{m}^{-2}\right)$, (middle) rain rate $\left(\mathrm{mm} \mathrm{day}^{-1}\right)$, and (right) low-level cloud amount (\%) for the global warming case compared with present-day conditions (1999-2008). Shown are results obtained with the integral constraint method (solid lines) and with a tuned version of the Liu et al. (2007) autoconversion scheme (dashed lines, tuning factors are given in brackets). Results shown are for horizontal model resolutions of $0.5^{\circ} \times 0.5^{\circ}, 1^{\circ} \times 1^{\circ}$, and $2^{\circ} \times 2^{\circ}$.

used here has been specifically tuned to reproduce lowlevel marine clouds in this region whereas in global models commonly the same tuning is applied to all different kinds of clouds (low-, mid-, and high-level, marine and continental clouds).

\section{b. Dependence of cloud sensitivity on model tuning}

While the integral constraint method is scale aware and does not need to be adjusted for different horizontal resolutions, conventional autoconversion schemes have to implicitly account for unresolved subgrid-scale variability of cloud properties by, for instance, adjusting the rain formation efficiency. As discussed above, the Liu et al. (2007) scheme provides much higher rain formation rates than Khairoutdinov and Kogan (2000) and so performs well when implemented in iRAM at $0.5^{\circ} \times$ $0.5^{\circ}$. For the coarser resolutions, however, iRAM systematically overestimates cloud water using the Liu et al. (2007) scheme. We therefore tuned the rain formation efficiency by increasing the autoconversion rate for the $1^{\circ} \times 1^{\circ}$ experiment by $50 \%$ and for the $2^{\circ} \times 2^{\circ}$ simulation by $100 \%$.

Figure 8 shows 10 -yr mean changes in zonally averaged (over the longitude range $160^{\circ}-60^{\circ} \mathrm{W}$ ) LWP, daily rain rate, and low-level cloud amount due to global warming relative to present-day conditions. Particularly for the response of daily rain rates to global warming as well as changes in LWP, we find that the differences among the model experiments at different horizontal resolutions are larger than those between the tuned conventional autoconversion scheme and the integral constraint method. This suggests that taking the subgridscale variability of clouds implicitly into account by carefully tuning a conventional autoconversion scheme provides results for the response of low-level clouds to global warming similar to the observationally constrained autoconversion scheme. However, we would like to point out again that no conclusions can be drawn from these experiments for clouds with a significant ice phase such as in the case of mixed phase clouds or deep convection because the integral constraint method in its current form can only be applied to warm clouds (section 2a). Note also that all three horizontal resolutions give a qualitatively similar response of cloud properties and precipitation to global warming.

To investigate the impact of autoconversion tuning on different cloud regimes, we compare local feedback parameters obtained with Liu et al. (2007) with results obtained with the integral constraint method for different regions. We divide the model domain into the following subregions: Northeast Pacific stratocumulus region $\left(120^{\circ}-140^{\circ} \mathrm{W}, 15^{\circ}-30^{\circ} \mathrm{N}\right)$, Southeast Pacific stratocumulus region $\left(82^{\circ}-96^{\circ} \mathrm{W}, 15^{\circ}-5^{\circ} \mathrm{S}\right)$, Pacific trade wind regime $\left(140^{\circ}-150^{\circ} \mathrm{W}, 15^{\circ}-30^{\circ} \mathrm{N}\right)$, Atlantic trade wind regime $\left(65^{\circ}-75^{\circ} \mathrm{W}, 15^{\circ}-30^{\circ} \mathrm{N}\right)$, equatorial Pacific region $\left(115^{\circ}-145^{\circ} \mathrm{W}, 4^{\circ} \mathrm{S}-4^{\circ} \mathrm{N}\right)$, and the entire model domain $\left(60^{\circ}-160^{\circ} \mathrm{W}, 30^{\circ} \mathrm{S}-30^{\circ} \mathrm{N}\right)$. Figure 9 shows the domain averaged local feedback parameters for these regions at the three horizontal resolutions $0.5^{\circ} \times 0.5^{\circ}$, $1^{\circ} \times 1^{\circ}$, and $2^{\circ} \times 2^{\circ}$. The stratocumulus regions and the Northeast Pacific and Northwest Atlantic trade wind regimes show strong positive cloud-climate feedbacks at all horizontal resolutions and for both autoconversion schemes. Average local feedback parameters range from about $2 \mathrm{~W} \mathrm{~m}^{-2} \mathrm{~K}^{-1}$ in the Atlantic trade wind region at $0.5^{\circ} \times 0.5^{\circ}$ to $4.5 \mathrm{~W} \mathrm{~m}^{-2} \mathrm{~K}^{-1}$ in the Northeast Pacific stratocumulus region $\left(0.5^{\circ} \times 0.5^{\circ}\right)$. On average, model simulations using the integral constraint method 

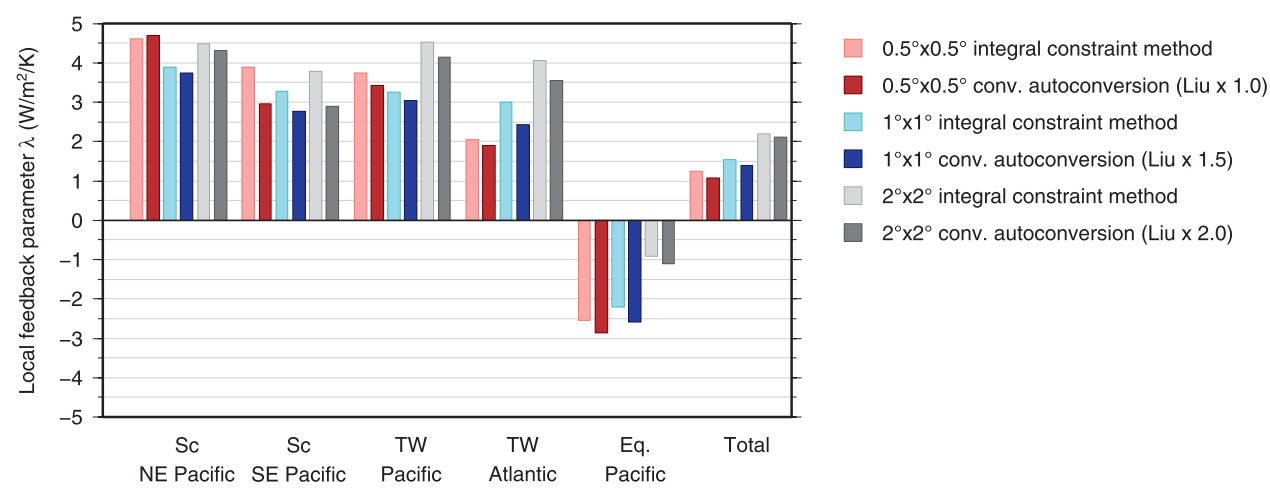

FIG. 9. Comparison of domain averaged 10-yr means of the feedback parameter $\lambda\left(\mathrm{W} \mathrm{m}^{-2} \mathrm{~K}^{-1}\right)$ for the Northeast (NE) and Southeast (SE) Pacific stratocumulus (Sc) regions, the Pacific and Atlantic trade wind (TW) regime, the equatorial (Eq) Pacific, and averaged over the whole model domain (total) obtained with the integral constraint method and with a tuned conventional autoconversion scheme (Liu et al. 2007). Shown are results for the horizontal resolutions $0.5^{\circ} \times 0.5^{\circ}, 1^{\circ} \times 1^{\circ}$, and $2^{\circ} \times 2^{\circ}$. The tuning factors for the conventional autoconversion scheme are given in brackets. For definitions of the regions see text.

show a cloud sensitivity to global warming about $10 \%-$ $15 \%$ higher than in the corresponding simulations with the tuned conventional autoconversion scheme. Consistent with this more positive cloud feedback, the integral constraint method also gives a $10 \%-15 \%$ weaker cloud response (less negative) in the equatorial Pacific compared with the Liu et al. (2007) autoconversion scheme. Averaged over the entire model domain, the integral constraint method gives an about 5\%-15\% stronger (more positive) cloud response than the conventionally tuned autoconversion parameterization. These differences are, however, smaller than the differences between the different horizontal model resolutions. We therefore conclude that tuning of the precipitation formation efficiency in warm clouds to present-day conditions does not significantly affect results for the response of low-level marine clouds to global warming. This is an important result because it reassures that the common practice of tuning cloud schemes by adjusting the efficiency of warm rain formation to improve agreement with observations is reasonable and can be applied to climate change scenarios. Furthermore, our results suggest that tuning of the autoconversion efficiency is likely not a leading reason for the large spread in cloud-climate feedbacks and therefore climate sensitivities shown by current state-of-the-art global climate models.

\section{Summary and conclusions}

We performed two sets of model experiments using the International Pacific Research Center's Regional Atmospheric Model (iRAM): 1) 1-yr integrations at horizontal resolutions between $0.25^{\circ} \times 0.25^{\circ}$ and $2^{\circ} \times 2^{\circ}$ to evaluate the scale awareness of the integral constraint method and to compare those results to the ones obtained with two conventional autoconversion schemes; and 2) 10-yr integrations for present-day and late twenty-first century conditions using the integral constraint method and with a tuned conventional autoconversion scheme to assess the impact of autoconversion tuning on results for the cloud sensitivity to global warming.

Comparisons of results from iRAM for present-day conditions showed that the integral constraint method does not only give reasonably good agreement with observations for key parameters such as liquid water content and shortwave cloud forcing, but also gives consistent results at different horizontal resolutions without the need for additional tuning of the rain formation scheme. In contrast, the two tested conventional autoconversion schemes overestimate liquid water path and shortwave cloud forcing particularly at resolutions coarser than $0.5^{\circ} \times 0.5^{\circ}$. The reason for this overestimation in cloud water and shortwave cloud forcing is unrealistically small precipitation formation rates and consequent overestimation of cloud lifetime. When using gridbox mean values as input parameters for nonlinear cloud microphysical processes such as rain formation, neglecting the subgrid-scale variability of cloud properties results in biases that increase as the horizontal model resolution decreases. This intercomparison also showed that while the integral constraint method provides consistent vertical liquid water content profiles at different horizontal resolutions for low-level clouds, which are predominant in the VOCALS-REx region, this is not the case for deep convection in the ITCZ. The assumptions made in the integral constraint method using satellite observations to constrain rain 
formation in warm clouds are not valid for mixed phase or ice phase clouds and a conventional rain formation parameterization is used whenever the cloud ice to cloud liquid water ratio exceeds $10 \%$. No conclusions can therefore be drawn for deep convective clouds.

To assess the impact of autoconversion tuning on the cloud response to global warming, we examined cloudclimate feedbacks in the East Pacific region using prescribed boundary conditions for late twenty-first-century conditions. The model simulations using the pseudoglobal-warming method were conducted at horizontal resolutions of $0.5^{\circ} \times 0.5^{\circ}, 1^{\circ} \times 1^{\circ}$, and $2^{\circ} \times 2^{\circ}$. We compared results obtained with the scale-aware integral constraint method with results obtained with the tuned conventional autoconversion scheme from Liu et al. (2007). These model simulations show that the geographical pattern and the amplitude of the cloud response to global warming quantified by the local feedback parameter are not greatly different whether they are obtained with the integral constraint method or the tuned conventional autoconversion scheme. However, the cloud sensitivity to global warming obtained using the integral constraint method is found to be about $10 \%-30 \%$ higher than that obtained with the conventional approach in the Southeast Pacific stratocumulus regions as well as the Northeast Pacific and Northwest Atlantic trade wind regimes. In the Northeast Pacific stratocumulus region, the cloud sensitivity to global warming does not depend significantly on the choice of autoconversion scheme. In the equatorial East Pacific, the cloud sensitivity to global warming drops by $10 \%-$ $15 \%$ (becoming more positive) when the integral constraint method is used, with the degree of sensitivity here depending somewhat on the horizontal model resolution. Averaged over the entire domain, clouds simulated with the integral constraint method are about $5 \%-15 \%$ more sensitive to global warming than in the results obtained with the conventional autoconversion scheme. The differences between the feedbacks among the horizontal resolutions examined are generally larger than those caused by changing between the integral constraint method and the Liu et al. (2007) scheme.

Note that given the large uncertainties in the modeled cloud response to global warming in general, those differences among the different horizontal resolutions can be considered small, increasing the confidence in the results from our previous work. Lauer et al. (2010) found a strong positive cloud-climate feedback of low-level marine clouds over the eastern Pacific and, in particular, a cloud feedback in this that was larger than displayed by current global coupled models. This result has important implications for the projection of future climate change and this study can be considered an attempt to examine the robustness of the Lauer et al. (2010) findings. In particular the present study shows that the basic result of Lauer et al. (2010) is fairly robust to changes in horizontal model resolution and to the details of the treatment of cloud water conversion processes. Our results suggest that use of a carefully tuned conventional autoconversion scheme may be adequate to assess cloudclimate feedbacks of low-level marine clouds. This is particularly the case for the two stratocumulus decks in the East Pacific. Our present results further suggest that the possible uncertainty in simulation of cloud feedbacks due to the treatment of autoconversion is modest and does not play a major role in explaining the large spread in climate sensitivity among current state-of-theart climate models. However, because of the restriction of the integral constraint method to warm clouds, no conclusion can be drawn for clouds with a significant mixed phase or ice phase such as in the case for deep convective clouds or typical mid- and high-latitude clouds. Another limitation of the integral constraint method is that it remains unclear whether the LWP PDF obtained from observations changes significantly in future climate. Future studies will help to address this uncertainty by analyzing the LWP variability as a function of anomalies in SST and lower tropospheric stability (LTS) as well as the El Niño-Southern Oscillation (ENSO) state. We also would like to point out that while we have not found the details of the warm rain formation parameterization to have a strong impact on results for the cloud response to global warming, this might not be the case for indirect aerosol effects. Rotstayn (2000) and Golaz et al. (2011), for instance, found a large impact of autoconversion on indirect effects, which are also important for global warming.

Acknowledgments. This research was supported by the Japan Agency for Marine-Earth Science and Technology (JAMSTEC), by NASA through Grant NNX07AG53G, and by NOAA through Grant NA09OAR4320075, which sponsor research at the International Pacific Research Center. This research was also supported by NOAA/CPPA Grant NA07OAR4310257 and DOE Regional and Global Climate Modeling (RCGM) Program Grant ER64840. NCEP FNL data for this study are from the Research Data Archive (RDA), which is maintained by the Computational and Information Systems Laboratory (CISL) at the National Center for Atmospheric Research (NCAR). NCAR is sponsored by the National Science Foundation (NSF). NCEP-NCAR reanalysis data have been provided by the NOAA/OAR/ ESRL PSD, Boulder, Colorado, available from their web site (http://www.cdc.noaa.gov/). CERES data were obtained from the Atmospheric Science Data Center at 
NASA Langley Research Center. VOCALS-REx data are provided by NCAR/EOL under sponsorship of the National Science Foundation, http://data.eol.ucar.edu/. All model calculations were performed at the Hawaii Open Supercomputing Center (HOSC).

\section{REFERENCES}

Bender, F. A.-M., 2008: A note on the effect of GCM tuning on climate sensitivity. Environ. Res. Lett., 3, 1-6, doi:10.1088/ 1748-9326/3/1/014001.

Bennartz, R., A. Lauer, and J.-L. Brenguier, 2011: Scale-dependent integral constraints on autoconversion and accretion in regional and global climate models. Geophys. Res. Lett., 38, L10809, doi:10.1029/2011GL047618.

Bony, S., and J.-L. Dufresne, 2005: Marine boundary layer clouds at the heart of tropical cloud feedback uncertainties in climate models. Geophys. Res. Lett., 32, L20806, doi:10.1029/ 2005 GL023851.

- - and Coauthors, 2006: How well do we understand and evaluate climate change feedback processes? J. Climate, 19, 3445 3482.

Clement, A. C., R. Burgmann, and J. R. Norris, 2009: Observational and model evidence for positive low-level cloud feedback. Science, 325, 460-464.

Geoffroy, O., J. L. Brenguier, and I. Sandu, 2008: Relationship between drizzle rate, liquid water path and droplet concentration at the scale of a stratocumulus cloud system. Atmos. Chem. Phys., 8, 4641-4654.

Golaz, J.-C., M. Salzmann, L. J. Donner, L. W. Horowitz, Y. Ming, and M. Zhao, 2011: Sensitivity of the aerosol indirect effect to subgrid variability in the cloud parameterization of the GFDL atmosphere general circulation model AM3. J. Climate, 24, 3145-3160.

Guo, H., J.-C. Golaz, L. J. Donner, V. E. Larson, D. P. Schanen, and B. M. Griffin, 2010: Multi-variate probability density functions with dynamics for cloud droplet activation in largescale models: Single column tests. Geosci. Model Dev., 3, 475486, doi:10.5194/gmd-3-475-2010.

Hartmann, D. L., and D. Doelling, 1991: On the net radiative effectiveness of clouds. J. Geophys. Res., 96 (D1), 869-891.

Khairoutdinov, M., and Y. Kogan, 2000: A new cloud physics parameterization in a large-eddy simulation model of marine stratocumulus. Mon. Wea. Rev., 128, 229-243.

Kimura, F., and A. Kitoh, 2007: Downscaling by pseudo-globalwarming method. ICCAP Final Rep., Research Institute for Humanity and Nature (RIHN), Kyoto, Japan, 43-46.

Knutsen, T. R., J. J. Sirutus, S. T. Garner, G. A. Vecchi, and I. M. Held, 2008: Simulated reduction in Atlantic hurricane frequency under twenty-first century warming conditions. Nat. Geosci., 1, 359-364.

Larson, V. E., R. Wood, P. R. Field, J. C. Golaz, T. H. Vonder Haar, and W. R. Cotton, 2001: Systematic biases in the microphysics and thermodynamics of numerical models that ignore subgrid-scale variability. J. Atmos. Sci., 58, 1117-1128.

Lauer, A., Y. Wang, V. T. J. Phillips, C. S. McNaughton, R. Bennartz, and A. D. Clarke, 2009: Simulating marine boundary layer clouds over the eastern Pacific in a regional climate model with doublemoment cloud microphysics. J. Geophys. Res., 114, D21205, doi:10.1029/2009JD012201.

_ , K. Hamilton, Y. Wang, V. T. J. Phillips, and R. Bennartz, 2010: The impact of global warming on marine boundary layer clouds over the eastern Pacific-A regional model study. J. Climate, 23, 5844-5863.

Liu, Y., P. H. Daum, R. L. McGraw, M. A. Miller, and S. Niu, 2007: Theoretical expression for the autoconversion rate of the cloud droplet number concentration. Geophys. Res. Lett., 34, L16821, doi:10.1029/2007GL030389.

Loeb, N. G., B. A. Wielicki, D. R. Doelling, G. L. Smith, D. F. Keyes, S. Kato, N. Manalo-Smith, and T. Wong, 2009: Toward optimal closure of the earth's top-of-atmosphere radiation budget. J. Climate, 22, 748-766.

Medeiros, B., B. Stevens, I. M. Held, M. Zhao, D. L. Williamson, J. G. Olson, and C. S. Bretherton, 2008: Aquaplanets, climate sensitivity, and low clouds. J. Climate, 21, 4974-4991.

Meehl, G. A., C. Covey, T. Delworth, M. Latif, B. McAvaney, J. F. B. Mitchell, R. J. Stouffer, and K. E. Taylor, 2007: The WCRP CMIP3 multimodel dataset: A new era in climate change research. Bull. Amer. Meteor. Soc., 88, 1383-1394.

Ming, Y., V. Ramaswamy, L. J. Donner, and V. T. J. Phillips, 2006: A new parameterization of cloud droplet activation applicable to general circulation models. J. Atmos. Sci., 63, 1348-1356.

O'Dell, C. W., F. J. Wentz, and R. Bennartz, 2008: Cloud liquid water path from satellite-based passive microwave observations: A new climatology over the global oceans. J. Climate, 21, 1721-1739.

Phillips, V. T. J., L. J. Donner, and S. T. Garner, 2007: Nucleation processes in deep convection simulated by a cloud-systemresolving model with double-moment bulk microphysics. J. Atmos. Sci., 64, 738-761.

— , P. J. DeMott, and C. Andronache, 2008: An empirical parameterization of heterogeneous ice nucleation for multiple chemical species of aerosol. J. Atmos. Sci., 65, 2757-2783.

— aerosols on ensembles of continental clouds simulated numerically. Biogeosciences, 6, 987-1014.

Pincus, R., and S. A. Klein, 2000: Unresolved spatial variability and microphysical process rates in large-scale models. J. Geophys. Res., 105 (D22), 27 059-27 065.

Raymond, D. J., and Coauthors, 2004: EPIC2001 and the coupled ocean-atmosphere system of the tropical east Pacific. Bull. Amer. Meteor. Soc., 85, 1341-1354.

Reynolds, R. W., T. M. Smith, C. Liu, D. B. Chelton, K. S. Casey, and M. S. Schlax, 2007: Daily high-resolution-blended analyses for sea surface temperature. J. Climate, 20, 5473-5496.

Rotstayn, L. D., 2000: On the "tuning" of autoconversion parameterizations in climate models. J. Geophys. Res., 105 (D12), 15 495-15 507.

Sanderson, B. M., and Coauthors, 2008: Constraints on the model response to greenhouse gas forcing and the role of subgridscale processes. J. Climate, 21, 2384-2400.

Sato, T., F. Kimura, and A. Kitoh, 2007: Projection of global warming onto regional precipitation over Mongolia using a regional climate model. J. Hydrol., 333, 144-154.

Solomon, S., D. Qin, M. Manning, M. Marquis, K. Averyt, M. M. B. Tignor, H. L. Miller Jr., and Z. Chen, Eds., 2007: Climate Change 2007: The Physical Science Basis. Cambridge University Press, 996 pp.

Stevens, B., and G. Feingold, 2009: Untangling aerosol effects on clouds and precipitation in a buffered system. Nature, 461, 607-613.

Stowasser, M., and K. Hamilton, 2006: Relationship between shortwave cloud radiative forcing and local meteorological variables compared in observations and several global climate models. J. Climate, 19, 4344-4359. 
Tiedtke, M., 1989: A comprehensive mass flux scheme for cumulus parameterization in large-scale models. Mon. Wea. Rev., 117, $1779-1800$

vanZanten, M. C., B. Stevens, G. Vali, and D. H. Lenschow, 2005: Observations of drizzle in nocturnal marine stratocumulus. J. Atmos. Sci., 62, 88-106.

Wang, L., Y. Wang, A. Lauer, and S.-P. Xie, 2011: Simulation of seasonal variation of marine boundary layer clouds over the eastern Pacific with a regional climate model. J. Climate, 24, 3190-3210.

Wang, Y., S.-P. Xie, H. Xu, and B. Wang, 2004: Regional model simulations of marine boundary layer clouds over the Southeast Pacific off South America. Part I: Control experiment. Mon. Wea. Rev., 132, 274-296.

Watanabe, M., S. Emori, M. Satoh, and H. Miura, 2009: A PDFbased hybrid prognostic cloud scheme for general circulation models. Climate Dyn., 33, 795-816, doi:10.1007/s00382-0080489-0.

Wielicki, B. A., B. R. Barkstrom, E. F. Harrison, R. B. Lee III, G. L. Smith, and J. E. Cooper, 1996: Clouds and the Earth's Radiant Energy System (CERES): An Earth Observing System experiment. Bull. Amer. Meteor. Soc., 77, 853-868.

Wood, R., 2000: The validation of drizzle parametrizations using aircraft data. Proc. 13th Int. Conf. on Clouds and Precipitation, Reno, NV, International Association of Meteorology and Atmospheric Sciences, 530-533.
_ 2005a: Drizzle in stratiform boundary layer clouds. Part I: Vertical and horizontal structure. J. Atmos. Sci., 62, 3011-3033. 2005b: Drizzle in stratiform boundary layer clouds. Part II: Microphysical aspects. J. Atmos. Sci., 62, 3034-3050.

—, P. R. Field, and W. R. Cotton, 2002: Autoconversion rate bias in stratiform boundary layer cloud parameterizations. Atmos. Res., 65, 109-128.

— T. L. Kubar, and D. L. Hartmann, 2009: Understanding the importance of microphysics and macrophysics for warm rain in marine low clouds. Part II: Heuristic models of rain formation. J. Atmos. Sci., 66, 2973-2990.

—_ and Coauthors, 2011: The VAMOS Ocean-Cloud-AtmosphereLand Study Regional Experiment (VOCALS-REx): Goals, platforms, and field operations. Atmos. Chem. Phys., 11, 627654.

Wyant, M. C., and Coauthors, 2010: The PreVOCA experiment: Modeling the lower troposphere in the Southeast Pacific. Atmos. Chem. Phys., 10, 4757-4774.

Yang, B., Y. Qian, G. Lin, R. Leung, and Y. Zhang, 2011: Some issues in uncertainty quantification and parameter tuning: A case study of convective parameterization scheme in the WRF regional climate model. Atmos. Chem. Phys. Discuss., 11, 31 769-31 817, doi:10.5194/acpd-11-31769-2011.

Yuan, J., Q. Fu, and N. McFarlane, 2006: Tests and improvements of GCM cloud parameterizations using the CCCMA SCM with the SHEBA data set. Atmos. Res., 82, 222-238. 